\title{
DESMONTANDO LA FORTALEZA (ROSA) EUROPEA: UN ANÁLISIS CRÍTICO SOBRE LA POLÍTICA DE ASILO Y REFUGIO POR MOTIVOS DE ORIENTACIÓN SEXUAL
}

\author{
Autor: Sergio Moreno Ríos \\ sergio.morenorios@gmail.com \\ Escuela de Gobierno (UCM)
}

\begin{abstract}
"Si algo así como una Ética LGTBQ es pensable y deseable, ha de partir del hecho de que la lucha contra la homofobia no puede darse aisladamente haciendo abstracción del resto de injusticias sociales y de discriminaciones, sino que la lucha contra la homofobia sólo es posible y realmente eficaz dentro de una constelación de luchas conjuntas solidarias en contra de cualquier forma de opresión, marginación, persecución y discriminación. Repito. No por caridad. Sino porque la homofobia, como forma sistémica de opresión, forma un entramado muy tupido con el resto de formas de opresión, está imbricado con ellas, articulado con ellas de tal modo que, si tiras de un extremo, el nudo se aprieta por el otro, y si aflojas un cabo, tensas otro. Si una mujer es maltratada, ello repercute en la homofobia de la sociedad. Si una marica es apedreada, ello repercute en el racismo de la sociedad. Si un obrero es explotado por su patrón, ello repercute en la misoginia de la sociedad. Si un negro es agredido por unos nazis, ello repercute en la transfobia de la sociedad"
\end{abstract}

Paco Vidarte

Bienaventurados los perseguidos por causa de la justicia, porque de ellos es el Reino de los Cielos. 


\title{
Resumen
}

La asociación de la homofobia con la inmigración, el asilo y el refugio, ha venido a gestar una política homonacionalista que brota como una instrumentalización de la ciudadanía no heterosexual y la homofobia que ésta padece. Al mismo tiempo, se ha venido a demostrar como la fortaleza rosa europea invisibiliza del imaginario social y jurídico a la otredad homosexual y bisexual migrada dificultando que pueda solicitar asilo o encontrar refugio dentro de la Unión Europea.

Palabras Clave: política de asilo y refugio por motivos de orientación sexual; estudios queer; interseccionalidad; homonacionalismo; choque de la ignorancia; pánico moral; auto-explotación; Unión Europea.

Deconstruting the european (pink) fortress: a critical analysis of refugee and asylum policies for sexual orientation reasons

\begin{abstract}
The association of homophobia with immigration, asylum and refuge, has come to generate a homonationalist policy that springs up as an instrumentalization of non-heterosexual citizenship and homophobia that it suffers. At the same time, it has come to show how the European pink fortress makes invisible from the social and legal imaginary to homosexual and bisexual migrated otherness making it difficult for them to seek asylum or find refuge within the European Union.
\end{abstract}

Key words: asylum and refugee policy on grounds of sexual orientation; queer studies; intersectionality; homonationalism; clash of ignorance; moral panic; self-exploitation; European Union. 


\section{INTRODUCCIÓN}

«El señor Ratib Nabulsi, interviniendo en el Congreso de la UOIF ${ }^{1}$ del norte de 2016, afirmó que "la homosexualidad conduce a la destrucción del homosexual. Esta es la razón, mis queridos hermanos, por la que el castigo a la homosexualidad ha de ser la pena de muerte (...) Como verá el pueblo francés, es necesario erradicar la ideología fundamentalista y, usted, no lo hará porque está sometido a ellos, le controlan” (...) Y para eso urge tanto si se es hombre o mujer, heterosexual u homosexual, salir del armario como francés y defender los intereses de Francia - M. LE PeN

Este debate ha tenido ya al menos un mérito formidable: escuchar de su boca palabras de compasión hacia los homosexuales de este país a los que sigue negando sus derechos civiles. La lucha contra el terrorismo será la prioridad en los próximos años y la dirigiré con firmeza dando a las fuerzas de seguridad más recursos (...) Usted continúe con sus insultos, yo creo que la cuestión es saber si los franceses quieren el espíritu de derrota que usted encarna (...) o el de conquista que siempre ha cosechado triunfos para esta nación y su ciudadanía- E. MACron»

Debate Presidencial Le Pen - Macron 2017 (France 2, 2017)

Resulta curiosa la creciente presencia de diálogo en torno a la sexualidad en los debates políticos europeos sobre una lucha antiterrorista que preludia su incipiente manifestación en el patriotismo, el belicismo y la oposición a una mundialización antagónica a la tolerancia y permisividad sexual de Occidente. Verbigracia, tanto Le Pen como su adversario presidencial, Macron, destacan aquí la confluencia de la sexualidad y la política de asilo y refugio europea. Así pues, la metáfora del armario que, como cree Kaplan, la ultraderecha invoca a fin de asimilar con mayor facilidad la efigie de Europa como fortaleza, resulta tanto insólita por su diseminación apropiativa, como por la confiscación a la que alude. Por un lado, la convergencia de la candidata con la jerga homosexual marca un periodo sociocultural de inclusión nacional de la homosexualidad que bosqueja un permisible paralelismo entre la liberación homosexual y la liberación nacional. Frente a ello, en su incisiva crítica durante el debate, Macron señala astutamente la debilidad de las declaraciones de la líder del Frente Nacional francés incurriendo, desafortunadamente, en una omisión de otro orden. En sí, al focalizar su respuesta a través de la vía de la defensa y la seguridad, los derechos y libertades que posibilitan toda posible salida del armario vienen a reconocerse para con un ideal de ciudadanía limitado, excluyente con la población migrada aún y cuando parte de la misma huye del horror que ambos candidatos repudian, aparentemente, dentro y fuera de sus fronteras estatales.

\footnotetext{
${ }^{1}$ Acrónimo que identifica a la Unión de organizaciones islámicas de Francia.
} 
En consonancia, sin discursos tales como los presentes sobre la sexualidad, los mecanismos paralelos de normalización y exclusión que disciernen al terrorista del patriota dejarían de funcionar según se espera de los mismos. A tenor de ello y siguiendo paralelamente a Puar (2017), el reconocimiento y la inclusión nacional se supeditan a la segregación y descalificación de los otros migrados del imaginario nacional a partir de una dinámica en la que interviene una forma de excepcionalidad sexual pasajera del sujeto no heterosexual estatal. En otras palabras, la asociación de la homofobia con inmigración, asilo y refugio, ha venido a gestar un discurso bajo la denominación académica de homonacionalismo, cuya representación surge como una cosmovisión que instrumentaliza a la ciudadanía heterodisidente y la homofobia que ésta padece,gracias a la creación y negación simultánea de poblaciones de otros sexuales-raciales que no parecen tolerables con, como se acomete a falsar o verificar aquí, consecuencias aviesamente homófobas.

A priori, la idea de fortaleza que se sostiene en este trabajo implica una noción de restricción geográfica y temporal; un relato escondido de auge y decadencia basado en una excepcionalidad que sitúa a la Unión Europea por encima de la misma, erigiéndolo como árbitro y mediador de la corrección ética, los derechos humanos y el proceder democrático, al tiempo que ultraja sus propios mandatos universalizantes. Como se verá, en esta coyuntura histórica, el imperio de la sexualidad no es sino renegociado a través de un pánico moral que invoca al terrorista como a un otro extranjero a fin de estructurar el guion que regula la guerra contra el terrorismo en una Unión Europea que vive hoy presa de una situación excepcional de xenofobia institucional, en la que los organismos comunitarios y los gobiernos de los Estados miembros están respondiendo al mayor desplazamiento de población desde la Segunda Guerra Mundial. Bajo el presente paradigma, una multitud de dirigentes europeos ha venido a justificar sus políticas racistas y xenófobas como una fortaleza que preserve la democracia sexual; esto es, los derechos de las personas no heterosexuales situadas en el seno de la Unión Europea.

A este supuesto, conceptualizado como homonacionalismo, se propone aquí añadir un parámetro analítico y descriptivo adicional: la alianza entre el racismo inherente al mismo y la homofobia que tiende a pasar inadvertida por la academia. En este sentido, se hipotetiza la relación de la homofobia con el homonacionalismo no bajo el discurso ya tradicional que ha venido a anunciar la instrumentalización de las personas homosexuales y bisexuales para legitimar la xenofobia y el racismo social e institucional, sino a partir de un relato que, pese a enunciar lo previo igualmente, entiende y denuncia el homonacionalismo como una estrategia mediante la que el heterosexismo se relaciona bajo representaciones homonormativas. Es decir, si bien se admiten los antecedentes académicos que sostienen cómo en parte la legitimación de la ciudadanía no heterosexual 
en Occidente fue sólo posible a través de un giro histórico sólo tolerado gracias al proceso paralelo que habilita su distinción de las poblaciones que son víctimas de segregación, exclusión o exterminio (Alexander, 1996), se cuestiona aquí el reconocimiento efectivo del derecho a la existencia que la fortaleza rosa europea otorga. En pos de ello, a lo largo del artículo se vendrá a falsar o verificar cómo este movimiento de construcción de la otredad, de demarcación racial a través de multitudes queer, admite la incorporación progresiva de sujetos normativos excepcionales a la gestión biopolítica de la vida, en tanto que ésta se complementa por el número cada vez mayor de cuerpos heterodisidentes extranjeros o no nacionales que son encaminados a morir en pos de la estratificación erótico-racial. Por lo tanto, se cree aquí que el derecho a la existencia no es incondicional, pues desposee al cuerpo no heterosexual de humanidad supeditándolo a su situación nacional-administrativa mediante un contrato, entre la Europa fortaleza y las periferias afectivo-sexuales, en clave de (falsa) promesa de protección para los suyos y de muerte para los otros.

En suma de todo ello, existen una multiplicidad de medidas a considerar y analizar, desde y bajo una perspectiva interseccional cruzada entre la disidencia afectivo-sexual y la racialización, elaboradas y planteadas por la Unión Europea y los parlamentos nacionales. Como es sabido, la interseccionalidad alude a todo enfoque que reniegue de la secesión de categorías identitarias en vista a una aproximación exhaustiva de múltiples dimensiones de la vida social (Platero, 2012), resaltando la suma de derivaciones que permean los componentes jurídicos, políticos y socioculturales concernientes a cada realidad investigada (Brah \& Phoenix, 2004). Tal cual lo evidenciaría Rubin, el sistema de opresión sexual atraviesa otros modos de desigualdad social extraviando a individuos o grupos según su intrínseca dinámica interna basada en la clase, etnia o identidad sexual, que pueden aminorar o acrecentar los efectos de dicha estratificación (1989). Huelga señalar, asimismo, como el uso que aquí se hace del término racialización no aparecerá tanto ligado a las enraizadas teorías de la raza, como a un concepto aplicable a alineaciones y procesos sociales, excluyentes o disgregadores, que vienen a promover un trato desigual u opresivo (McCall, 2005) para con "un grupo concebido como natural, un grupo de humanos considerado como materialmente específico en sus cuerpos" (Guillaumin, 1992, p. 7). En definitiva, se piensa aquí imprescindible que este estudio comprehensivo y de resistencia al homonacionalismo atienda al conglomerado de opresiones que interactúan entre sí, visibilizando tanto la homonormatividad social e institucional en su estrategia heterosexista, como los procesos de racialización y la barbarie de ambas que, lejos de ser excluyentes, conforman esa cosa escandalosa que se hace llamar realidad (Haraway, 1991). 
Por lo pronto, a lo largo del presente trabajo de investigación, se pretenderán analizar las distintas problemáticas colectivas que pudieran coexistir imposibilitando, tanto a las personas perseguidas por razón de su orientación sexual ejercer su derecho humano a la protección internacional, como la inacción de los Estados a cumplir con sus compromisos internacionales, europeos y constitucionales de promover, proteger y garantizar el ejercicio de los derechos humanos para con las personas refugiadas por motivos de orientación sexual, incluidos, entre ellos, el derecho de asilo en su sentido más holístico. Para ello, se categorizarán y desarrollarán distintos criterios susceptibles de estar siendo aplicados en las personas solicitantes de asilo y refugio no heterosexuales; a saber, invisibilización, enmascaramiento, criminalización e incredulidad. De esta forma, resultará posible desentrañar la incondicionalidad o no del derecho a la existencia que otorga la democracia sexual europea y, por tanto, la racialización o concesión de derechos de ciudadanía en función de la situación nacional-administrativa de las personas no heterosexuales. Además, brevemente, se tratará de analizar la propia situación de ciudadanía de las personas homosexuales y bisexuales dentro de la Unión Europea -esto es, la presunción de pluralismo de la misma- desde una mirada focalizada en la política de asilo y refugio, a fin de desvelar el carácter permanente o pasajero de la excepcionalidad de la democracia sexual y del consenso para el reconocimiento y la incorporación de los cuerpos no heterosexuales nacionales. Finalmente, aceptando que los hallazgos científicos resultan valiosos en su complejo carácter específico y circunstanciado (Geertz, 1977), se tomará a España como factor de control (Burke, 2000) en tanto que país con mayor tasa de aceptación de la diversidad afectivo-sexual (Pew Research Center, 2018), en vistas a entrever la posible racialización de los cuerpos heterodisidentes.

Así pues, "Desmontando la fortaleza (rosa) europea" busca ser una invitación sociológica a explorar en mayor profundidad las conexiones entre sexualidad y raza con relación a las técnicas, estrategias y lógicas de las maquinarias de construcción de una fortaleza europea en lo referente a las políticas contemporáneas de asilo y refugio. Este proyecto critica la promoción, la administración y la valoración asimétrica de la vida y de todo aquello que la sustenta, describiendo los aparatos mediante los cuales los procesos de racialización conforman las axiomáticas distancias entre la vida y la muerte, la seguridad y la inseguridad, el derecho o la ausencia al refugio. De esta manera, se exhiben aquí las preguntas y formulaciones abiertas que han suscitado el presente estudio: ¿cuáles son las vinculaciones en este periodo histórico marcado por la afluencia masiva de personas refugiadas en torno a la crisis nacional, la crisis del Estado de derecho y de los valores europeos, y la patologización de una sexualidad racializada y extranjera? ¿Cómo se ejerce la inevitable violencia institucional que condena a esos iguales ahora racializados en pos de construir una fortaleza europea? ¿Han sido 
directa o indirectamente abandonadas a la muerte las multitudes queer víctimas de persecución y/o solicitantes de asilo y refugio? ¿Cuáles son los supuestos heteronormativos sobre el análisis, la administración, la elaboración y la gestión de las políticas de asilo y refugio europeas? ¿Qué fatalidad dialéctica ha venido a filtrarse por las fisuras homófobas del homonacionalismo europeo?

Recapitulando, las preguntas rectoras de esta empresa y la estrategia de investigación que las sucederá, vendría a acoger en su seno y proseguir con el precepto interrogativo que ha guiado los estudios queer tras los trágicos atentados acaecidos el 11-S:

"Es posible seguir siendo receptivos a nuevas formas de pertenencia, conectividad, a los deslizamientos y las productividades involuntarias e indeterminadas de la dominación, para señalar una futuridad de políticas afectivas?" (Puar, 2017, p. 40)

Finalmente, y de cara a la operacionalización, se enuncian aquí las hipótesis descriptivas, organizadas en tipologías flexibles que no requieren de exhaustividad ni significados unívocos (Alguacil et al, 2014), que el investigador procederá a falsar guiado por un diseño metodológico de corte cualitativo:

Hipótesis principal $\left(\mathrm{H}^{1}\right)$. El carácter racializado de la fortaleza: en tanto que la fortaleza rosa europea, legitimada en su ideario homonacionalista y materializada en su política de asilo y refugio, habría venido ocultando del imaginario social y jurídico la segregación, exclusión o exterminio de la otredad heterodisidente que anhelase refugio dentro de la Unión Europea, el derecho humano a la vida o a la existencia de las personas homosexuales y bisexuales no sería incondicional, pues dependería de la situación nacional-administrativa de las mismas.

De la misma, como se ha venido adelantando, se desprende otro supuesto que, debido a la limitación temporal y espacial del investigador, sólo alcanzará a ser presentado y parcialmente comprobado en clave de hipótesis secundaria:

Hipótesis secundaria $\left(\mathrm{H}^{2)}\right.$. El carácter dialéctico de la fortaleza: los discursos y políticas homonacionalistas, al ser una estrategia del heterosexismo, esconderían la homofobia que se vendría produciendo en y desde la Unión Europea, desvelando dialécticamente el carácter pasajero de la excepcionalidad de la democracia sexual y del consenso para el reconocimiento y la incorporación de los cuerpos homosexuales y bisexuales nacionales.

No obstante, y como se ha venido advirtiendo, el obligado deber de exigencia y sistematicidad, de integridad analítica y de rigor científico, lejos de sosegar las ansias y espíritu de un trabajo que se exhibe a sí mismo como un interruptor 
para el cambio, hace de los mencionados imperativos un utilitarismo que afronta conscientemente las resistencias, contradicciones y conflictos inherentes a toda investigación crítica y socialmente comprometida. Tal es así que en el marco de un estudio sobre la realidad de los solicitantes de asilo no heterosexuales situados en el florecimiento de la fortaleza europea, no es posible sino delimitar los siguientes capítulos en la definición que Speed sentencia sobre la investigación activista: aquella que, partiendo del "análisis crítico cultural", termina penetrando en un "compromiso explícito por trabajar en colaboración con los sujetos de estudio, hacia objetivos políticos compartidos" (Speed, 2006, p. 7) con el fin de alcanzar una "conciencia emancipada y verdadera, adecuada al compromiso político y al estudio de los sistemas" (Vallés, 2009, p. 56).Y así, en el devenir del desarrollo intersubjetivo que ha encaramado las políticas contemporáneas de asilo y refugio, resultará posible articular, en términos wittigianos, una ciencia de la opresión gestada por los propios oprimidos:

"La conciencia de la opresión no es sólo una reacción (una lucha) contra la opresión. Supone también una total revaluación conceptual del mundo social, su total reorganización con nuevos conceptos, desarrollados desde el punto de vista de los oprimidos" (Wittig, 1992, p. 22).

Con todo, tras el análisis descriptivo-discursivo resultará la presentación de aquellos resultados que respondan a las preguntas planteadas mediante los hallazgos arrojados y, a partir de ellos, se dispondrán las conclusiones y limitaciones últimas de las hipótesis y del estudio. En efecto, las páginas que prosiguen son el esfuerzo de hilar un relato científico sustentando en un marco teórico, con la vocación instrumental de bienvenida y acogida, para la edificación de una Europa que no deje atrás a nadie.

\section{MARCO TEÓRICO: ESTADO DEL ARTE Y DE LA CUESTIÓN}

"Inventar el espacio para leer el mundo".

Jacques Levy (2010)

Así como todo lienzo que se pretenda trazar y esbozar requiere de un marco desde el que ser observado y juzgado, el análisis científico apremia de andamiajes teórico-conceptuales apropiados y reconstruidos por un investigador que se aproxima y toma contacto con el fenómeno en cuestión. En este sentido, se exige aquí bosquejar un preludio teórico que no sólo arguya a los presupuestos que han permitido identificar las problemáticas complejas que afectan al objeto de estudio, 
sino que enmarque la propuesta de investigación empírica previa, permitiendo articular el conglomerado de proposiciones teóricas al hilo del conjunto de herramientas metodológicas que proseguirán para con el análisis académico y su correspondiente interpretación. Por tanto, urge cuestionar, en un primer momento, la emergencia de la fortaleza europea en su articulación material, esto es, en su política de asilo y refugio (Wittig, 1992), para indagar después en los procesos de racialización de una democracia sexual homonacionalista que conforma las axiomáticas distancias entre la vida y la muerte, y que perpetúa el orden hegemónico a través de los resultados políticos que desprende.

\section{LA CONSTRUCCIÓN DE LA FORTALEZA EUROPEA}

Así pues, bajo la aspiración de realizar una aproximación veraz a las políticas de asilo y refugio, y dado que la hipótesis descriptiva no viene sino a afirmar el papel mediador de las instituciones entre las identidades y los resultados políticos, el análisis multidisciplinar que procederá, vendrá a ser orientado dentro de un marco constructivista social que asuma el sistema internacional como el resultado de un significante intersubjetivo; es decir, como un cuerpo de ideas, pensamientos y normas que emergen dictadas a nivel social en un periodo y en un territorio determinado (Ruggie, 1975). En concordancia con el presente paradigma, se asume que las instituciones europeas, comprendidas como complejos normativos, conforman las identidades de los Estados y, consecuentemente, sus intereses y su comportamiento político (Wendt, 1999).

En pos de ello, particularmente ejemplarizantes resultan aquí las reflexiones sobre los debates contemporáneos de los Estados Unidos de América como imperio mundial. Para Kaplan "negar y repudiar la idea de imperio ha sido durante mucho tiempo el fundamento ideológico del imperialismo americano y un elemento básico de su excepcionalidad" (2004, p. 14). Paradójicamente entonces, repeler la excepcionalidad del imperio arroja un resultado divergente al representar a los EE. UU. como una potencia superior, no subordinada a las fallas e inestabilidades ordinarias que conducen a los imperios a su extinción, y que subsiste amparada en los discursos moralizantes que resignifican las violencias del imperio en clave ética, política y sociocultural (Fial-Matta, 2002). Con todo, cabe señalar como el atentado terrorista contra las Torres Gemelas de Nueva York llevó a los EE. UU. a reforzar y consagrar su papel imperial. Siguiendo a Rey Pérez (2006), desde la ominosa fecha del 11 de septiembre de 2001, los Estados occidentales asumen un rol defensivo ante su ciudadanía y excusan en el mismo su falaz incapacidad para solventar la crisis del Estado social que asola desesperadamente a la ciudadanía que dicen proteger. Sintéticamente, los propios Estados propagan, bajo una óptica neoliberal, la percepción de inseguridad a fin de evitar hacer frente a la pobreza y 
exclusión social, en aras a salvaguardar su pervivencia ante una globalización que preludia su decadencia (Rey Pérez, 2006).

En efecto y también en la propia Europa posmoderna marcada por la globalización neoliberal, el aumento de los flujos migratorios ha supuesto la reagrupación de la nacionalidad y la identidad como nexo común frente a una otredad extranjera concebida, como señala Martínez de Pisón, "en términos de avalancha del bárbaro sobre la civilización occidental” (Álvarez González, 2006, p. 200). Como afirma Álvarez González, parece factible que el fundamento de tal exclusión encuentre su respuesta en la concepción de los derechos humanos como privilegios occidentales; escenario amurallado, en gran medida, por una escasez material que induce a que decretados derechos se conciban como parte de una riqueza nacional que viene a vetar a aquellos ajenos a la comunidad (Álvarez González, 2006). Finalmente, en esta "justificación de las fronteras frente a los derechos fundamentales" (De Lucas, 2006, p. 69), favorecida a su vez por la sensación de inseguridad, los Estados asumen "la lucha contra la inmigración como una actividad estatal de supervivencia" (Rey Pérez, 2006, p. 271) y se apropian del sentir de sus oprimidos nacionales para, como se verá, la edificación de su nueva empresa: una fortaleza entendida aquí como una restricción geográfica y temporal, como un feudo de los derechos humanos y del proceder democrático que aplica una política de aislamiento frente a terceros países, particularmente en los derechos de asilo e inmigración, que ultraja sus propios mandatos universalizantes (Milborn, 2006).

No resulta así extraño que, en el último lustro europeo, en el que los organismos comunitarios y los gobiernos de los Estados miembros estarían respondiendo tanto al mayor desplazamiento de población desde la Segunda Guerra Mundial como al mismo terrorismo interno que empuja al éxodo del pueblo sirio, la propia política de asilo y refugio europea haya venido a gestarse hondamente embebida por su política migratoria. Así, obedeciendo a una cosmovisión sumamente economicista y securitaria basada en el control de flujos, y no tanto en los aspectos humanitarios y de desarrollo que jurídicamente debieran guiarla, los Estados estructuran el guion que regula la lucha contra el terror y la creciente desigualdad en una Unión Europea que vive hoy presa de una situación excepcional de xenofobia institucional para con las personas refugiadas (CEAR, 2016).

Bajo este paradigma, urge a continuación realizar un esfuerzo investigador por trazar una línea socio-jurídica acerca de las fuentes del derecho que versen sobre el fenómeno de las personas refugiadas en su situación material y, haciendo especial énfasis, con respecto a la fortaleza europea. En este menester, las fuentes jurídicas por antonomasia que asisten a la comentada realidad nacen y deben su ser al Derecho Internacional Público: un sector surgido como consecuencia de las relaciones transfronterizas entre las comunidades políticas estatales. 
Por lo pronto, el movimiento de grandes masas humanas empujadas por razones de índole tanto religiosa como económica, política e incluso naturales, es posible rastrearlo en el ADN de las civilizaciones humanas. Ya las Sagradas Escrituras ponen de relieve las constantes diásporas que el pueblo judío padeció, así como el destino azaroso de aquellos grupos considerados marginales en una España capitaneada por los Reyes Católicos ${ }^{2}$ y en época de Felipe III $^{3}$, entre otros ejemplos. Evidentemente, en la Edad Moderna es todavía imposible hablar de una Comunidad Internacional preocupada por la suerte de esas personas debido a dos factores: por un lado, las relaciones mantenidas entre los Estados se limitaban a una tímida comunicación diplomática compuesta por gentilhombres, solamente interesados en hacer próspero su país; por otro, y más interesante si cabe, los Derechos individuales, de corte iusnaturalista, no se consagraron hasta la promulgación de la Declaración de los Derechos del Hombre y del Ciudadano de 1789 (Rodríguez Carrión, 2007).

Curiosamente, el quebrantamiento de prácticamente todos esos principios por parte de los simpatizantes del Nazismo (1939-1945) fue lo que sirvió de pretexto para crear, por fin, un marco jurídico que diera asistencia a las personas refugiadas. Es la Organización de las Naciones Unidas, originada asimismo por la onda expansiva de la Segunda Guerra Mundial, el primer y único instrumento internacional que tiene como objetivo preocuparse sobre dicha situación estableciendo hojas de ruta y mecanismos para afrontar la problemática mediante la Convención de Ginebra sobre el Estatuto de los Refugiados de 1951 y su Protocolo de Nueva York de 1967. Obviamente, ambos se desarrollaron bajo la estela de la renombrada Declaración Universal de los Derechos Humanos de 1948, concretamente de su art. 14: "En caso de persecución, toda persona tiene derecho a buscar asilo, y a disfrutar de él, en cualquier país. Este derecho no podrá ser invocado contra una acción judicial realmente originada por delitos comunes o por actos opuestos a los propósitos y principios de las Naciones Unidas". La herramienta práctica que, en nombre de la ONU, emprende, regula e informa sobre estas medidas es el Alto Comisionado de las Naciones Unidas para los Refugiados ${ }^{4}$ (Trujillo Herrera, 2003).

Si bien la Convención de Ginebra pretendió dar cobertura a los afectados por la Segunda Guerra Mundial ${ }^{5}$, se jacta por haber acuñado el concepto "refugiado" en los siguientes términos (art. 1): "cualquier persona que debido a fundados temores de ser perseguida por motivos de raza, religión, nacionalidad, pertenencia a un determinado grupo social u opiniones políticas, se encuentre fuera del país

\footnotetext{
${ }^{2}$ Edicto de expulsión del 30 de marzo de 1492 que legalizaría una nueva salida de los judíos.

${ }^{3}$ Edicto de expulsión de los moriscos del 30 de enero de 1608.

${ }^{4}$ En adelante ACNUR.

${ }^{5}$ Ámbito subjetivo corregido/ampliado en el Protocolo de 1967.
} 
de su nacionalidad y no pueda o, a causa de dichos temores, no quiera acogerse a la protección de su país; o que careciendo de nacionalidad y hallándose, a consecuencia de tales acontecimientos fuera del país donde antes tuviera su residencia habitual, no pueda o, a causa de dichos temores no quiera regresar a él". Asimismo, la Convención ginebrina consagró en su art. 33.2 la prohibición sobre la devolución del refugiado -principio de non-refoulement- siempre y cuando las circunstancias conflictivas que motivaron su marcha persistieran, entre otras garantías (Gortazar, 1997).

En lo que respecta al espacio de la Unión Europea, varias son las ideas que urge destacar. En primer lugar, el derecho originario, es decir, el Tratado de Unión Europea $^{6}$ y el Tratado sobre el Funcionamiento de la Unión Europea ${ }^{7}$, contempla la realidad de los las personas refugiadas en su articulado inspirándose en los principios internacionales mencionados supra, redactándose de esta guisa los artículos 3.2 $\mathrm{TUE}^{8}$ y 78.1 $\mathrm{TFUE}^{9}$. Será entonces el derecho derivado posterior, mediante Reglamentos de aplicación directa, y Directivas necesitadas de transposición al derecho interno, el que vendría a matizar ese marco general. En este sentido, las diferentes pretensiones sobre el derecho de asilo y de la concesión de la condición de refugiado han llevado a iniciar un itinerario legislativo que recibe el nombre de Sistema Europeo Común de Asi ${ }^{10}$, dando debido cumplimiento a la exigencia del art. 78.2 TFUE. Se trata de un paquete de medidas que pretende armonizar la legislación y establecer procedimientos y condiciones comunes para el tratamiento de las solicitudes de asilo. Su eficacia ha sido aplicada en múltiples fases, atendiendo a situaciones y sensibilidades diferentes, siendo el originario el Programa Tampere (1999-2004), seguido del Programa de La Haya (2005-2010), del de Estocolmo (2011-2015) y encontrándose en fase de reforma en la actualidad.

En segundo lugar, es perceptible la misma preocupación hacia las personas refugiadas en la Carta de Derechos Fundamentales de la Unión Europea ${ }^{11}$, cuyo art. 18 expresa: "se garantiza el derecho de asilo dentro del respeto de las normas de la Convención de Ginebra de 28 de julio de 1951 y del Protocolo de 31 de enero de 1967 sobre el Estatuto de los Refugiados y de conformidad con el Tra-

${ }^{6}$ En adelante TUE.

${ }^{7}$ En adelante TFUE.

8 "La Unión ofrecerá a sus ciudadanos un espacio de libertad, seguridad y justicia sin fronteras interiores en el que esté garantizada la libre circulación de personas conjuntamente con medidas adecuadas en materia de control de las fronteras exteriores, asilo, inmigración y de prevención y lucha contra la delincuencia".

9 "La Unión desarrollará una política común en materia de asilo, protección subsidiaria y protección temporal destinada a ofrecer un estatuto apropiado a todo nacional de un tercer país que necesite protección internacional y a garantizar el respeto del principio de no devolución".

${ }^{10}$ En adelante SECA.

${ }^{11}$ En adelante CEDH. 
tado constitutivo de la Comunidad Europea", sin olvidar la alusión al principio de non-refoulement del art. 19. Ídem podría decirse de la normativa comunitaria y, de forma menos evidente, del Convenio Europeo de Derechos Humanos ${ }^{12}$ y los Protocolos que le siguen.

Por otro lado, "ante la incapacidad de asumir", en palabras de la Comisión, "tal ingente marea humana” (Comisión Europea, 2016), el 29 de noviembre de 2015 se estableció un Plan de Acción Conjunto entre la UE y la República de Turquía (Medidas operativas de la cooperación UE-Turquía en el ámbito de la migración). En su tercera sesión de marzo de 2016 se convino que la Antigua Constantinopla se hiciera cargo de toda persona migrante que arribara en las costas griegas, esto es, potenciales personas refugiadas y resto de desplazadas de cualquier condición, recibiendo en contraprestación una serie de prerrogativas por parte de la UE. Primero, una cantidad económica consistente en 3.000 millones de euros ampliables para afrontar la responsabilidad; segundo, la eliminación de visados para la ciudadanía turca que desee cruzar las fronteras interiores de la UE y, finalmente, abrir la negociación para la adhesión de Turquía a la UE. Esta última se comprometió a que, por cada persona siria deportada desde Grecia, la Unión acogería a una persona refugiada siria por el tratamiento legal ordinario, reservando 72.000 plazas orientativas para esta empresa. Mucha literatura y controversia se ha generado acerca de la dudosa licitud de esta ingente medida por infringir los Derechos Humanos de las personas desplazadas, por no mencionar el rechazo que suponen el atajo que Bruselas concede a un Estado en plena deriva autárquica con el fin de conseguir la membresía de la Unión. Asimismo, preocupa la violenta reducción de la UE a la hora de asumir como personas refugiadas a aquellas empujadas por la guerra: exclusivamente la población siria (Gortazar, 2016).

Una vez escaneados los panoramas internaciones y supranacionales, brevemente, en España el derecho de asilo se encuentra amparado bajo el art. 13.4 de la Constitución: "la ley establecerá los términos en que los ciudadanos de otros países y los apátridas podrán gozar del derecho de asilo en España”. Efectivamente, se trata de la Ley 12/2009, de 30 de octubre, reguladora del derecho de asilo y de la protección subsidiaria la que se ocupa de su desarrollo normativo. Como dato que será analizado posteriormente, merece apuntar que España, durante la legislatura de José María Aznar -1997-, pretendió consolidar un Protocolo dentro del Tratado de Ámsterdam, estableciendo que ningún Estado de la Unión admitiera a trámite una petición de asilo o refugio formulada por un nacional de otro Estado de la Unión. Sin embargo y si bien organizaciones como Amnistía Internacional y el ACNUR manifestaron su rechazo a la iniciativa, la misma prosperó y aún hoy sigue vigente (Rodríguez Carrión, 2007).

\footnotetext{
${ }^{12}$ En adelante EASO.
} 
En esta tesitura, no parece sencillo vaticinar la situación y supervivencia de la UE debido al gran golpe que la denominada crisis de los refugiados ha asestado a los cimientos de la misma. De hecho, son la incertidumbre e inseguridad las que han generado y despertado la alarma: aunque las cifras de personas desplazadas actuales se perciben elevadísimas, se desconoce si disminuirán, se mantendrán o aumentarán. En cualquiera de los casos, las instituciones de la UE han activado nuevamente su lenta maquinaria para afrontar esta incógnita futura. Así, un comunicado de la Comisión Europea de 2016 dispuso una serie de novedades que vendrían a reformar el marco actual de la UE a fin de garantizar una política de asilo humana y eficiente; en otras palabras, un nuevo Programa que tomara el testigo al de Estocolmo, visto supra, fundamentado en los principios de responsabilidad y solidaridad.

En definitiva y por todo lo expuesto, se admitirá para con el siguiente análisis un -incumplido- marco jurídico de aplicación y defensa del conjunto de la ciudadanía humana que traspase la fortaleza que, de unos para otros, se ha venido forjando; pues, como señala Peces-Barba:

"Por tener en su raíz la dignidad humana, fuente de la moralidad pública, que cristaliza en los derechos, todos afectan a las dimensiones básicas del libre desarrollo de la personalidad y todos son derechos humanos y no sólo del ciudadano" (Peces-Barba, 1994, p. 433).

\section{LA CONSTRUCCIÓN DE LA DEMOCRACIA SEXUAL HOMONACIONALISTA}

A continuación, y en vistas a realizar una reflexión crítica en torno a la sexualidad y la raza para esclarecer la construcción de una otredad que legitime y edifique la fortaleza europea que se acude aquí a analizar, se urge partir de Bourdieu, en tanto que no resulta útil "negar las permanencias y las invariantes que forman una parte incontestable de la realidad social", sino que parece "preciso reconstruir la ciencia mediante un trabajo sociológico de deconstrucción" (Bourdieu, 2000, p. 106). Es decir, al asumir que "la comprensión de la extrañeza requiere de un estudio del régimen que lo crea" (Phelan, 2001), se ha de plantear una huída de los senderos de las "ciencias normales" (Guasch, 1995, p. 1) para embarcarse en el estudio de la alteridad no como ajena o extrínseca al sistema de heterosexualidad obligatoria, sino como algo producido por dicho sistema como su margen o frontera; esto es, depurando la forma y reproducción de las estructuras de estratificación y exclusión que perviven, para con esta exploración académica, en el régimen internacional en general y en el sistema europeo en particular.

Como se verá, tal y como la organización capitalista del trabajo dispone de su propia política interna basada en la desigual y opresiva distribución de 
recompensas y poderes, el reino de la sexualidad, en sus formas institucionales concretas, se halla tanto deliberada como inconscientemente imbuido y configurado por conflictos de intereses y estratagemas que exhortan y recompensan a determinados individuos y prácticas al tiempo que sancionan y oprimen a unos y a otras (Rubin, 1989). Debido a ello, este epígrafe destapa y desnuda el modo en el que el moderno sistema de estratificación sexual ha sido objeto de embates políticos desde que emergió y que, como tal, ha venido desdoblándose de forma más o menos mistificada y camuflada en las sociedades occidentales a raíz de periodos históricos, como el coetáneo, en los que la existencia sexual se ha visto sagazmente impugnada o públicamente politizada.

El mundo heterosexual, la sociedad azul para Guasch, presa de las categorías mentales del heterocentrismo, se niega analizarse a sí mismo a través de la picaresca científicamente freudiana de deducir la normalidad a partir de los individuos que contradicen, refutan e incumplen las normas sociales (Guasch, 1995). De esta forma, se invisibiliza la institución heterosexual al presentarla como un presupuesto anterior a todo orden social, impidiendo realizar ese giro dialéctico indispensable si lo que se pretende es percibir y cuestionar sus cimientos constitutivos. Se muestra así lógico que la antropología, etnología o la propia sociología dominante, dada la incomodidad que pueda suscitar toda reformulación de las enraizadas fronteras entre lo público y lo privado, lo masculino y lo femenino, lo azul y lo rosa, no hablen tanto de Contrato social y sí de status quo; es decir, de algo ontológico que no habría de mudar jamás. ¿Cuál es por tanto ese pensamiento que rechaza examinarse a sí mismo, que se ve incapaz de cuestionar la raíz primigenia sobre la que se fundamenta? Aquel que se basa en la heterosexualidad y que es el pensamiento de la dominación (Wittig, 1992).

En oposición a la exégesis crudamente economicista de la historia que patrocina el marxismo, se toma aquí una reinterpretación de la misma cimentada en el sexo pues cada matiz de la civilización humana ha estado y está mediada por la estructura de clase sexual (Firestone, 1970). Al esbozar esto, se muestra la heterosexualidad no ya exclusivamente como una institución, sino como el Contrato social, como un régimen político racializador que sirve de parámetro a todas las relaciones jerárquicas (Wittig, 1992). Brevemente, con la invención del postulado laico e ilustrado del Contrato social, convenio, alianza o acuerdo entre individuos para la fundamentación del orden social, se trató de evidenciar cómo los individuos del estado de naturaleza permutaron la incertidumbre de la libertad natural por una libertad civil igual acorazada por el Estado. Sin embargo, en esta versión de la historia, la sociedad civil sólo pudo ser creada por medio de un contrato social asentado en el contrato sexual originario, escribiendo así un futuro de libertad en sujeción por el que la vida en sociedad consistía y consiste en vivir en heterosexualidad (Pateman, 1988). 
Desde este supuesto idealista es posible indagar en la teoría huntingtoniana en clave de emergencia ante un choque de civilizaciones que arguye a la fractura, una vez finalizada la Guerra Fría, entre los diversos conjuntos normativos cerrados y con capacidad de establecer una voluntad común inscrita a una determinada cosmovisión religiosa de todo aquello que aspiran a representar (Huntington, 1996). Tal y como señalan Toynbee y Quigley, el sistema de derechos humanos propiciado por Occidente, lejos de ser universal, no presenta credibilidad ante los conjuntos civilizatorios restantes, sino que ha sido y vendrá a ser percibido como un ente exógeno fundamentado en una fuerza irrevocable contra la que todas sus resistencias se han visto históricamente mermadas (Wendt, 1999). No obstante, y si bien Toynbee se preguntaría si Occidente alcanzaría a revertir la inevitable violencia que acontece al choque, universalizándose y perviviendo, Huntington prevé un final dialéctico para con esta civilización en clara minoría demográfica y anclada en una miscelánea de intereses con las restantes asociaciones étnico-culturales que componen el globo terráqueo (Huntington, 1996).

En contraposición al modelo, Edward Said ha venido a contrastar cómo el carácter estigmatizador de usos terminológicos tales como Occidente e Islam, encubren una solución categórica sobre una realidad ficticiamente alterada que viene a fortificar el orgullo nacional defensivo frente a la comprensión crítica de la interdependencia creciente de la contemporaneidad (2001). De acuerdo con la academia sucesora, este denominado choque de la ignorancia ha guiado el devenir de una suma de estudios sociales euro-estadounidenses que han articulado el mundo oriental en oposición para sí, como otredad categorizada por un islam determinado bajo la óptica etnocéntrica de Occidente (Brown, 2005). En efecto y del modo en que Cohen y Weeks teorizaron, se describe aquí un pánico moral que, cristalizando temores y ansiedades en torno a una amenaza percibida contra un valor o norma detentada por la sociedad occidental, se niega a escrutar las causas reales de la problemática a la que falsamente arguye desplazándolas a los "tipos diabólicos" o peligrosamente desviados de algún grupo social concreto (Cohen, 1980). Huelga recordar aquí, a modo de ejemplo, cómo ante la inminente crisis del Estado nacional estadounidense y apoyado en los atentados acontecidos el 11 de septiembre, la administración Bush se amparó en una sensación de inseguridad promovida a través de una cosmovisión islamófoba, por la que el Estado hizo de la guerra su propia actividad estatal de supervivencia (Rey Pérez, 2006).

En este sentido y para con el objeto de estudio de la presente investigación, Rubin advierte cómo, y resexualizando el concepto en clave de guerra sexual, una vez el furor de un pánico que "conduce temores y pasiones extraviadas e intensamente simbólicas contra objetivos falsamente relacionados” (Rubin, 1989, p. 36) culmine, algún grupo sexual desafortunado habrá sido exterminado y el Estado habrá extendido su poder "haciendo de los discursos sobre el sexo y de 
las tecnologías de normalización de las identidades sexuales un agente de control sobre la vida" (Preciado, 2010, p. 9). A propósito del imperio sexual, la academia ha encontrado que la penalización de los actos y las propias identidades afectivo-sexuales entre personas del mismo sexo procede, tanto de una aplicación determinada de la ley islámica o Sharia, como de vestigios y disposiciones jurídicas heredadas procedentes de la era colonial que nacían con la intención de reglamentar términos jurídicamente indeterminados como virtud, libertinaje o actos contra natura, y que en la actualidad fundamentan paradójicamente la percepción de la no heterosexualidad como prácticas occidentales no africanas o asiáticas (Ahmad, 2002). Dicho rastreo arqueológico apunta y visualiza la historia de un pasado y aún presente occidental que ha conocido y perpetuado el despotismo y el fundamentalismo, las violaciones sistemáticas de derechos humanos y ha contribuido en gran medida a la universalización del ideario heteropatriarcal que mina las libertades de las personas que aquí ocupan el análisis (Dow, 2002). A tenor de ello, actualmente y más allá de la criminalización socio-jurídica de la homosexualidad en aproximadamente el 40\% de los Estados que conforman la comunidad internacional, a razón de los informes de los órganos de tratados, los procedimientos especiales y los organismos de las Naciones Unidas, parece posible concluir que en la totalidad de las regiones humanas las personas no heterosexuales son víctimas, en mayor o menor medida, de una opresión sistemática que ha sido traducida como homofobia (Cantu, 2005). Además, de las monografías que recogen los elevados índices de violencia por dichas motivaciones existentes en cada civilización, se extrae que tales vulneraciones de derechos humanos pueden contener desde asesinatos, violaciones y agresiones físicas, torturas, tratos inhumanos y degradantes, detenciones arbitrarias, sustracción del ejercicio de los derechos de reunión, de expresión y de información, hasta la discriminación en el reconocimiento efectivo de los derechos sociales de empleo, salud, filiación y educación (CEAR, 2016).

De este pánico ignorante, la dicotomía occidente/oriente o, como señala Edelman, homosexualidad/islam en una de sus múltiples transfiguraciones, brota de un discurso sobre lo desproporcionado de ciertos posicionamientos subjetivos en un tira y afloja entre poblaciones que enfrentan islam a homosexualidad (2004). Paralela e indirectamente, la socióloga experta en genocidios Helen Fein, conceptualizó el "universo de las obligaciones" en aras a desentrañar el funcionamiento de los círculos de solidaridad entre personas que constituyen obligaciones recíprocas a partir de criterios de raza, sexualidad o territorio, delimitando la identidad dentro de la cual se posibilita forjar asuntos ético-morales y, por exclusión, la de todos aquellos que no forman parte de ese mismo vínculo (Fein, 1993). En esta misma línea, distintos autores han venido a agregar cómo las naciones heteronormativas occidentales contemporáneas se apoyan instrumentalmente en la 
propagación de cuerpos no normativos a través de la creación ideal de un sujeto homonacionalista, sexualmente excepcional, y su infame homólogo, la otredad terrorista extranjera y sin papeles (Edelman, 2004). Es más, tal y como han venido a señalar, el advenimiento contemporáneo de sujetos homosexuales y bisexuales normativos resulta ineluctable para la interacción entre la perversión y la normatividad que sostiene copiosamente la administración de la vida (Ahmad, 2002). Debido a esto último, ha venido a germinar una homonormatividad histórica y estratégica como medio por el cual el heterosexismo se relaciona con matrices alternativas o emergentes, incorporando nuevas realidades que transponen performativamente los horizontes de oportunidad (Moreno Sánchez \& Pichardo Galán, 2006). En conclusión, tales invitaciones al nacionalismo mediante relatos de excepción, bajo la excusa de la guerra contra el terrorismo, dejan entrever temporalmente en suspenso la comunidad estatal heteronormativa para la consolidación de un sentimiento nacional y un consenso por el reconocimiento y la incorporación de ciertos, más no todos, sujetos homosexuales y bisexuales en aras a la creación del Estado posmoderno. Surgen así, dentro del contrato social, fronteras intergrupales y jerarquizadas que Phelan definirá como "otros inapropiados", como "figuras ambivalentes que no son ni amigas ni enemigas: ni nosotros, ni claramente ellas" (Wittig, 1992); como las multitudes queer entendidas en esta investigación como cuerpos que no importan (Butler, 2002); esto es, como la otredad no heterosexual árabe, islámica y migrada que confronta la viabilidad de "las políticas universalistas que asientan el reconocimiento e imponen la integración de las diferencias en el seno de la República" (Preciado, 2010, p. 55). Dicho de otro modo, si bien históricamente la conformación de los Estados occidentales ha venido ligada a ideologías heteronormativas (Duggan, 2004), hoy los mismos han venido a gestar cosmovisiones homonormativas que regeneran y transcriben los ideales nacionales de raza, clase y género auxiliados por la fantasía de la permanencia de dicha suspensión (Fial-Matta, 2002). De este modo, las "prácticas reforzadas de los regímenes sexuales reguladores", del contrato de heterosexualidad obligatoria, impiden la elección libre y voluntaria de las identidades, formando las ideas, normas y visiones de todo lo que resulta posible y realizable (Butler, 2002, p. 214).

No es de extrañar, por tanto, que los estudios post-colonialistas aludan al concepto de pinkwashing con el propósito de denunciar la utilización estatal de los derechos de las personas homosexuales y bisexuales para la promoción de una imagen internacional defensora de los mismos (Ferguson, 2003). Así por ejemplo, urge recordar aquí los análisis que han venido a desentrañar las prácticas, actividades, eventos o campañas que presenta Israel como paraíso gay ajeno a las sociedades árabes homófobas de su entorno, a fin de encubrir las políticas de ocupación y violaciones sistemáticas de derechos humanos contra la población palestina y, 
especialmente, contra aquella extranjera cuya orientación sexual difiere de la norma (Buchanan, 2006). Recapitulando, parece entonces deducible que las políticas de reconocimiento e incorporación conllevan que ciertos sujetos homosexuales y bisexuales pueden ser receptores estacionales de las políticas de liberalidad que otorgan los discursos xenófobos en virtud de las demarcaciones de privilegio racial y del parentesco u origen nacional (Eng \& Shinhee, 2003). A razón de ello, en Ensamblajes terroristas, Jasbir K. Puar, anuncia el auge del homonacionalismo en los Estados Unidos, esto es, "el doble movimiento en virtud del cual ciertos grupos homosexuales y bisexuales han aceptado las agendas nacionalistas y han sido aceptados por ellas" (2017, p. 34). Como ha venido apuntándose, coincide en que las medidas antiterroristas se hallan estrechamente marcadas en parámetros de género, sexualidad y raza, y en que visualizan la gestación de superpuestas corporalidades hegemónicas, en clave dual patriota/terrorista, cohesionándose para sí (Puar, 2017). De este modo y en sintonía con Kaplan y Rey Pérez, dentro del teatro o farsa global, los Estados Unidos han pasado a representar y liderar la batalla imperial por los valores occidentales frente a un mundo reaccionario que amenaza con retornar a la oscuridad previa a la Ilustración. Y no es sino guiada por este mismo precepto que, en toda la Unión Europa, florecen nacionalismos sexuales que, según reseña el sociólogo Éric Fassin, obedecen a una vindicación excluyente de la otredad que camufla la xenofobia o racismo latente a partir de una segregación y exclusión legitimada en nombre y razón de la democracia sexual (2016).

De esta forma, la metamorfosis de los Estados-nación puede desvelar la alianza y trasfondo adyacente entre cosmovisiones heteronormativas conservadoras y el liberalismo homonacionalista. Valga especificar que esta coalición entre disposiciones nacionalistas radicales y homosexuales europeas no resulta peregrina en tanto que los derechos de la ciudadanía no heterosexual han comenzado a tornarse en el estandarte y enseña de una extrema derecha residual que tendía a proclamarse desde la tradición y las raíces, y cuyo repunte encuentra su explicación en la retórica islamófoba (Fassin, 2016). Efectivamente, del germen que contrapone homosexualidad a islam no ha tardado en surgir una respuesta racista en un continente donde el fenómeno de la extrema derecha populista hunde sus raíces en un miedo estrictamente relacionado con la denominada crisis de refugiados. A modo de muestra, un estudio del Instituto Allenbach ha constatado cómo mientras en el año 2004 la ciudadanía alemana mostraba sumo aperturismo a la llegada de población extranjera, en el año 2014 e iniciada la afluencia masiva de personas, un $67 \%$ dudaba que ésta pudiera llegar a integrarse (2016).

Dicho ideal que subyace fue acometido a finales de los años noventa por el político homosexual neerlandés Pim Fortuyn. Él mismo y tras adquirir el compromiso de aniquilar la inmigración irregular y el derecho de asilo empleando un discurso que apostaba por la defensa de unos valores europeos de libertad e 
igualdad sexual amenazados por la ciudadanía musulmana, logró aproximar a su partido a la mayoría parlamentaria tras su asesinato a manos de un animalista al que se caracterizó quiméricamente de islamófilo (Buchanan, 2006). A este aspecto la politóloga Yoshie Furuhashi afirmó que el triunfo de Pim Fortuyn inició una nueva era en las arengas homonacionalistas al promover intensamente políticas antiinmigración que velan una demagogia plagada de ofuscaciones islamófobas con un acuciado rédito electoral: "Fortuyn demostró que el populismo de derechas puede ser perfectamente gay además de enormemente popular" (Ferguson, 2004, p. 689).

Tras él, sus predecesores discursivos han encontrado para con la crisis de refugiados un importante arsenal con el que erigir y defender sus anhelos de fortaleza europea. Verbigracia, la exministra de Interior austriaca, Johanna Miki-Leitner, excusó el cierre de la ruta de los Balcanes en un supuesto antagonismo existente entre los ideales y sueños europeos, haciendo especial hincapié en los derechos de las personas homosexuales y bisexuales, y aun eludiendo que en Austria éstas no ven reconocido el matrimonio civil, con los de las personas refugiadas, invisibilizando además la orientación sexual de las mismas (Puar, 2017). En esta espiral hipócrita, la extrema derecha populista europea ha promocionado su retorno a la centralidad política subrayando los problemas que sufre la ciudadanía homosexual y bisexual en los barrios de mayoría musulmana. A modo de muestra, partiendo de sus homólogos francés y neerlandés que han venido aupando a dirigentes homosexuales en vistas a normalizar y hegemonizar su perorata islamófoba, David Coburn, eurodiputado homosexual y líder del UKIP escocés, declaró que de entre las personas que pudieran estar rebasando las costas británicas, una inmensidad de ellas parece acercarse deseosa de lapidarle (Fassin, 2016). En este punto, según Fassin, el problema radica no tanto en la credibilidad de líderes que aún hoy no reconocen la igualdad de derechos, sino en la fractura que trazan para la elección dicotómica de un campo de pensamiento: "tales discursos refuerzan una inquietud e idean una frontera peligrosa porque hacen creíble no a Marine Le Pen o al Frente Nacional, sino a una visión del mundo que opone ellos a nosotros en nombre de la democracia sexual" (Fassin, 2016, p. 77).

Por último y a razón de lo expuesto, el marco teórico acontece a la construcción de la biopolítica. Este concepto acuñado por la filósofa Rey Chow, hunde sus raíces y se define en la supremacía de la blanquitud; esto es, atando y enlazando las representaciones liberales de diversidad bajo la coartada de la valoración de la vida sobre todas las cosas, en aras a acceder a la explotación indómita de los propios sujetos que son incorporados en los discursos pluralistas en una primera instancia (Chow, 2006). Como señala entonces Han, el poder occidental contemporáneo, lejos de atacar la libertad, parece exaltarla y defenderla en una estructura en la que el individuo se piense libre y sólo alcance a encontrar enemigos 
externos a su libertad. Así, en oposición a las sociedades anteriores de carácter disciplinario, surge una evocación a la sociedad del rendimiento y de riesgo (Han, 2012) caracterizada por estar compuesta por sujetos falsamente autónomos que, en vistas a su propia seguridad, terminan por explotarse dialécticamente a sí mismos. Han desarrolla aquí el concepto de autoexplotación (2013), cerciorando que explotado y explotador es social e individualmente la misma persona. Con todo, este tipo de dominación, seductora y disimulada bajo una falsa apariencia de libertad, posee una mayor eficacia que las anteriores en tanto que el sujeto, acorralado por el terror, bunkeriza su existencia e impide, con la de sus pares, su propia liberación (Han, 2013).

En conclusión, a raíz del análisis que procederá en el próximo apartado, apura rematar aquí aseverando la presencia de una fortaleza europea entendida como una restricción geográfica y temporal, como un supuesto feudo de los derechos humanos y el proceder democrático que aplica una política aislacionista frente a terceros Estados, particularmente en los derechos de asilo e inmigración, que impele su legitimidad en un contrato de libertad en sujeción acorazado para el existir, entre otras, de la excepcionalidad de una democracia sexual que se cree amenazada por factores exógenos. Ante esta situación, se pretenderá a continuación desentrañar las grietas y fisuras homófobas de dicho contrato entre la Europa fortaleza y los sujetos normativos excepcionales, en aras a discernir la (falsa) promesa de protección para unos y de muerte para la otredad que esconde la fortaleza rosa europea.

\section{ANÁLISIS DESCRIPTIVO Y DEL DISCURSO: OPERACIONALIZACIÓN CONCEPTUAL}

"Vivíamos en los espacios en blanco en los bordes de la impresión. Eso nos dio mayor libertad. Vivimos en los huecos entre las historias".

Margaret Atwood (1985)

\section{LA FORTALEZA ROSA RACIALIZADA $\left(\mathrm{H}^{1}\right)$ : PROBLEMATIZANDO LA JURISPRUDENCIA}

Si bien previamente ha sido desglosado de forma sucinta el marco jurídico que atiende a la realidad de las personas refugiadas, se tratará ahora de invertir un esfuerzo analítico en relación a las personas solicitantes de la condición de refugiado debido a su orientación sexual; fenómeno que no es, ni mucho menos, extraordinario ni aislado. 
Como se ha venido adelantado, la persecución y penalización de las multitudes queer es un hecho factible en gran parte del planeta, generando a modo de factor de empuje un efecto reflejo de aquellos que pretenden escaparse de las distintas formas de opresión asimilables. Así pues, de acuerdo con una aplicación e interpretación evolutiva de la norma en función de la realidad social, en las últimas décadas tanto la normativa internacional como la europea han terminado extendiendo el ámbito subjetivo de aplicación del "derecho a tener derechos", como concibió el derecho de asilo la pensadora y filósofa Hannah Arendt (CEAR, 2016). Es por ello que a pesar de que los artífices de la Convención de Ginebra de 1951 no establecieran una cláusula específica para reconocer la persecución por razón de orientación sexual, el laxo precepto "pertenencia a determinado grupo social", junto con la raza, religión, nacionalidad y opiniones políticas consignadas en su art. 1, parece englobar la realidad que aquí atañe e incumbe: el ejercicio del mismo derecho a aquellas personas que son perseguidas por su orientación sexual e identidad de género (Directiva 2004/83/CE).

En cualquier caso, los Estados que conforman la Unión Europea no asisten a una práctica procesal del asilo uniforme en lo que aquí refiere. Así pues, países tales como Alemania, Finlandia, Reino Unido o Suecia, requieren tanto así la existencia de una norma punitiva en los países de origen que impliquen penas tales como la privación de libertad e, inclusive, la condena a muerte por incurrir en actos sexuales de naturaleza difusa entre personas del mismo sexo, como "el hecho de que se produzca de facto en tales Estados la aplicación efectiva de la norma punitiva" (Díaz de la Fuente, 2016). A su vez, otros Estados europeos han venido exigiendo no sólo la objetividad de la norma punitiva y su aplicación efectiva, sino también la materialización individualizada sobre el propio solicitante de protección internacional (Tsuordi, 2016).

Frente a ello, y con vistas a unificar criterios y actuaciones, el ACNUR, del mismo modo que con el Plan de los 10 puntos, supra, publicó en $2008^{13}$ una Nota de orientación sobre las solicitudes de la condición de refugiado relacionadas con la orientación sexual para mejorar el conocimiento de quienes toman decisiones sobre las experiencias específicas de los solicitantes de asilo LGBTI ${ }^{14}$ (CEAR, 2016).

Dentro del paquete de medidas del SECA, interesa sobremanera la Directiva 2011/95/UE sobre protección internacional, inserta en el Programa de Estocolmo (2011-2015). De la misma merece subrayar que los Estados miembros, además de acatar lo establecido por el art. 1 de la Convención de Ginebra en vistas a identificar como refugiado a una persona en función de su raza, religión, nacionalidad,

${ }^{13}$ Actualizado en 2012.

${ }^{14}$ La versión más actualizada de esas guías asistenciales ha sido proporcionada por la EASO en 2016. 
pertenencia a otro grupo social y opinión política, tendrán en cuenta aspectos relacionados con el sexo de las personas, incluyendo la orientación sexual y la identidad de género. Esta modificación se produjo debido a un estudio que relevó la existencia de considerables diferencias en la manera en que los Estados miembros trataban las solicitudes de este cariz (Migraciones forzadas, 2016). Además de ello, frente al carácter facultativo/potestativo de la redacción anterior, que señalaba que únicamente podrían tenerse en cuenta, la Directiva 2011/95/UE implica la obligatoriedad de cumplir los aspectos relacionados con la orientación sexual, tal y como evidencia su enunciado: tendrán que tenerse en cuenta (Tsuordi, 2016).

Por último y de acuerdo con la doctrina especializada, el derecho a la protección internacional en base al reconocimiento del estatuto de refugiado, inclusive el de las personas perseguidas por su orientación e identidad sexual, ha de ser concebido y forjado como un derecho humano, subjetivo, personalísimo y fundamental, cuya titularidad corresponde a la persona perseguida, pero cuyo reconocimiento queda vinculado al reconocimiento y la garantía holística del conjunto de derechos humanos restantes, ya sean el derecho a la vida, a la integridad o a la libertad (Gortázar, 1997). A tenor de ello, valga retornar aquí el CEDH que recoge la prohibición de la tortura declarando que "nadie podrá ser sometido a tortura ni a penas o tratos inhumanos o degradantes" (art. 3), y al CDFUE en tanto que proclama la dignidad humana afirmando que esta "es inviolable y será respetada y protegida" (art. 1), que "toda persona tiene derecho a su integridad física y psíquica" (art. 3.1), y establece la "prohibición de la tortura y de las penas o los tratos inhumanos o degradantes" (art. 4). Por lo mismo y si bien las Directivas 2004/83 y 2005/85 establecen, respectivamente, normas mínimas relativas a los requisitos para el reconocimiento y el estatuto de nacionales de terceros Estados como refugiados y los procedimientos de examen de las solicitudes de asilo, precisando a su vez los derechos de los solicitantes, el Tribunal de Justicia de la UE, en su sentencia en respuesta al Consejo de Estado de los Países Bajos, aclaró los métodos conforme a los cuales las autoridades nacionales pueden evaluar la credibilidad de la orientación sexual de los solicitantes de asilo. Así, se dictaminó en primer lugar que la valoración de las solicitudes asentada exclusivamente en prejuicios estereotipados coligados a las personas no heterosexuales no permite a las autoridades considerar la situación particular y las circunstancias personales de la persona solicitante. En segundo lugar, se prohíben los interrogatorios basados en los pormenores de las prácticas sexuales de la persona solicitante por ser contrarios a los derechos salvaguardados en la CDFUE y, en concreto, al derecho al respeto de la vida privada y familiar. En tercer lugar, a la posibilidad de que las autoridades nacionales admitan, como se han visto obligados a proponer diversas personas solicitantes de asilo, probatoriamente la práctica de actos sexuales con personas del mismo sexo, eventuales exámenes para verificar la orientación sexual 
o incluso la exposición de grabaciones de dichos actos, el Tribunal de Justicia insiste en que todo ello menoscaba la dignidad humana y equivaldría, por su efecto incentivador, de facto, a imponer al conglomerado de solicitantes tal tipología degradante de pruebas. En cuarto lugar, el Tribunal subraya que la no declaración de no heterosexualidad desde un primer momento por parte del solicitante no debe llevar a concluir a las autoridades que dicha persona carece de toda credibilidad (Migraciones Forzadas, 2016).

No obstante, la realidad material dista de obedecer a la normativa. Así, del análisis sintético de una multiplicidad de documentos elaborados por diversas organizaciones no gubernamentales sobre el tratamiento de las solicitudes de asilo fundamentadas en el riesgo de persecución de personas por motivos de orientación sexual desde la década de 1980 a la actualidad, parece posible elucidar cómo la jurisprudencia europea en materia de personas refugiadas ha conocido un desarrollo progresivo que, pese a todo, mantiene tanto aplicaciones divergentes en sus distintas jurisdicciones como fallas para el reconocimiento efectivo del derecho (Richard, 2016). Por tanto, del estudio crítico de los efectos colaterales de la misma en la población objetivo, conviene sistematizar científicamente la problemática a fin de revelar los corolarios de una política que se dice gestada para el cumplimiento de los derechos humanos. En este sentido, a partir del estudio crítico de la jurisprudencia producida en los que cabría esperar el auge de un homonacionalismo que brotase como un pánico moral derivado de la denominada crisis de refugiados, se conceptualizan y desarrollan aquí cinco criterios susceptibles de ser aplicados en indagaciones empíricamente observables, identificadas y categorizadas por el investigador a través del análisis exhaustivo de fuentes secundarias, para con las solicitudes de asilo y refugio de personas no heterosexuales; a saber, invisibilización, enmascaramiento, criminalización, incredulidad y presunción de pluralismo.

\subsection{Criterio de Invisibilización}

En primer lugar, como señala Türk, destaca oprobiosamente la invisibilización latente de la población homosexual y bisexual para con la elaboración y gestión de la política de asilo y refugio. Una invisibilización que obedece a ese pensamiento dominante que rechaza examinarse a sí mismo, que se ve incapaz de cuestionar la raíz primigenia sobre la que se fundamenta el contrato socio-sexual; esto es, la permutación de las tragedias de la libertad natural, que podrían llevar aquí a las personas a solicitar asilo, por un futuro de libertad civil en sujeción por el que la vida en sociedad consiste en vivir en heterosexualidad (Pateman, 1988).

En la actualidad, esa ortodoxia se manifiesta mediante "un pensamiento único" de pretensión universal que implica, como cultura, un "proceso social total" y, 
en tanto que ideología, un "sistema vivido de significados y valores que constituye la expresión o proyección de un particular interés de clase” (Wittig, 1992, p. 18). En este sentido y como se especificará a continuación, parece obvia la invisibilización de la política migratoria de asilo y refugio por motivos de orientación sexual a favor del pensamiento dominante; esto es, la omisión de las multitudes queer solicitantes de asilo, en pos de la dogmática neoliberal. Así y según se ha venido punteando, desde la designada crisis de refugiados y a través de una mirada holística sobre la realidad de dicha gestión, la propia política de asilo y refugio ha venido a gestarse hondamente embebida por una cosmovisión sumamente economicista y basada en el control de flujos, y no tanto en los aspectos humanitarios y de desarrollo que jurídicamente debieran guiarla (CEAR, 2016). En efecto y del modo en que Cohen y Weeks teorizaron, se describe aquí un pánico moral que, cristalizando temores y ansiedades en torno a una amenaza percibida contra un valor o norma detentada por la Unión Europea, se niega a escrutar las causas reales de la problemática a la que falsamente arguye desplazándolas a los "tipos diabólicos" o peligrosamente desviados de algún grupo social concreto (Cohen, 1980). Así, fruto del temor manifestado por el legislador y las autoridades comunitarias, tanto por el supuesto abuso del derecho de asilo de migrantes económicos como por la aprensión que infunde entre los Estados miembros el posible uso indebido del fraguado espacio de libertades para el crimen organizado internacional, se ha propiciado la incidencia de una acción nacional y comunitaria restrictiva con respecto al derecho humano a la protección internacional (Richard, 2016). En este sentido, desde la interseccionalidad, urge criticar y puntualizar que el reconocimiento del ejercicio efectivo al asilo no puede ser concebido mediante una política de corte generalista, esto es, como una solución última o aislada que no contemple la lucha específica contra la multiplicidad de opresiones existentes, entre las que destaca la homofobia, sino como un derecho humano integrado de modo coherente en un marco de justicia de mayor amplitud, cuyo destino sea la aplicación inclusiva, universal y no discriminatoria del Derecho Internacional de los Derechos Humanos (CEAR, 2016).

Desgraciadamente y lejos de corresponder a la realidad, la propuesta de Bruselas para la acotación del número de personas con acceso a refugio mediante cupos anuales, así como la reducción del concepto de asilo para únicamente aquellas personas que huyesen de un conflicto armado, vendría a comprimir las soluciones a la denominada crisis de refugiados mediante el compromiso de otorgar refugio de forma exclusiva a quienes huyesen de la guerra, obviando y excluyendo así la diversidad de características que acompaña a tales sujetos y que, como se ha venido advirtiendo, podrían estar padeciendo persecución por motivos tales como la orientación sexual (Migraciones forzadas, 2016). 
Asimismo, y debido a la propia invisibilización que encubre el carácter neoliberal de la política de asilo y refugio, la Unión Europea carece de información pertinente y específica relacionada con la situación y el trato de las personas homosexuales y bisexuales de múltiples países de origen (Türk, 2016). A razón de ello, encuentra especial relevancia el hecho de que CEAR haya insistido reiteradamente que la falta de información veraz sobre el ambiente homófobo no debiera instintivamente llevar a concluir que la solicitud del solicitante carezca de fundamento e invalide, como aún hoy viene sucediendo, los testimonios de los solicitantes por no ser éstos corroborables empíricamente (2016).

A su vez y sobre lo expuesto, caben mencionar los efectos desventajosos de la denominada lista común de países seguros, con cuya clasificación los legisladores europeos pretenden excluir del derecho de asilo a personas provenientes de lugares que las mismas consideran seguros. Si bien con el fin de fortalecer la protección de los menores no acompañados y otros grupos vulnerables, el concepto no se aplicará "en el caso de solicitantes pertenecientes a una minoría o un grupo de personas que permanecen en riesgo" (Comisión Europea, 2017), para Tsuordi la pretensión de incorporar a dicha lista Estados no seguros para las personas homosexuales y bisexuales acentúa la posibilidad de que las mismas vean agravadas las dificultades iníciales para ver reconocido su derecho al asilo, dado el origen seguro que se les presupone a tales países aunado a la escasa voluntad política sobre la materia que posee la Unión (Tsuordi, 2016).

Para la constatación de lo expuesto, huelga visualizar a modo de ejemplo la realidad de Kósovo, país propuesto junto a Albania, Bosnia y Herzegovina, Antigua República Yugoslavia de Macedonia, Montenegro, Serbia y Turquía, donde un creciente número de personas anhelan asilo dentro de la Unión a raíz de la persecución que sufren a causa de su orientación sexual (Fauchier, 2016). En efecto, como así insta encarecidamente Fauchier, más allá de la avanzada Constitución kosovar, inclusiva con el término orientación sexual en el artículo 24 destinado a erradicar la discriminación, la Unión habría de atenerse a la bien distinta realidad en la que se encuentra la población objetivo. Como es sabido, la discriminación contra las personas no heterosexuales en Kósovo es ejercida mayoritariamente por actores no estatales como la familia del solicitante de asilo o su comunidad más cercana, que vienen a forzar casamientos correctivos y someter a las personas a terapias contra lo que imaginan una perversión o enfermedad mental, cuando no a expulsarles de las mismas para un porvenir de marginación social (Migraciones forzadas, 2016). Sin embargo, debido a las teóricas garantías legales, el funcionariado adscrito a la concesión de las solicitudes de asilo tiende a denegarlo apelando a la protección jurídica sobre un papel que dista de implementarse sobre el terreno (Fauchier, 2016). Al parecer, el cuerpo policial no actúa con notoriedad contra la violencia estructural existente, y hasta la fecha nadie ha 
sido juzgado ante un tribunal por ningún caso de discriminación por razones de orientación sexual (Migraciones Forzadas, 2016). Como parece deducible y así se considera aquí, la incorporación de Kósovo a la lista de países seguros de la Unión Europea supondría una violación a todas luces de los criterios de Copenhague de respeto a los derechos humanos y protección de las minorías por los que, de acuerdo con la Comisión (2016), la misma debería valerse.

En todo caso, merece especial atención la última medida sobre la materia del ejecutivo alemán, que habría designado a los países del Magreb como seguros para el cuerpo refugiado queer, en aras a una aligerada repatriación de los demandantes de asilo de dicha condición, pese a la evidente persecución que sufren los mismos en las entrañas de tales Estados (Migraciones forzadas, 2016).

Junto a lo cerciorado y como es sabido, las políticas exteriores y migratorias de la Unión Europea poseen consecuencias directas sobre las vidas de las personas no heterosexuales en terceros Estados. Indudablemente, resulta pertinente detenerse a continuación en el Plan UE-Turquía de 20 marzo de 2016 que, como previamente se ha expuesto, ha suscitado una multitud de críticas por parte de distintos organismos y organizaciones de derechos humanos y de las personas refugiadas. A tenor de los mismos parece llamativo el consenso unánime sobre la vulneración de los derechos de las personas migrantes y refugiadas, así como de la normativa europea e internacional por parte del acuerdo entre ambos Estados. De esta forma, las mismas señalan como el acuerdo establece que los solicitantes de asilo en Grecia serán objeto de un procedimiento acelerado, según el cual no procederá examinar el fondo de la solicitud, que permitirá declarar inadmisible la misma cuando se considere que un tercer país, aquí Turquía, efectuaría dicho examen o brindaría una protección suficiente según los principios de "primer país de asilo" o de "tercer país seguro" recogido en los artículos 35 y 38 de la directiva de procedimientos (Amnistía Internacional, 2016). En opinión de CEAR, resulta irrisorio catalogar como país seguro a un Estado sobre el que recaen 2.899 casos sometidos al TEDH sobre los que, en un 93\%, se ha declarado violación del Convenio Europeo de Derechos Humanos. A su juicio, de aplicarse esta definición generalizada de Turquía como país seguro, se estaría trasladando la responsabilidad a un tercer Estado que no toma en consideración el conglomerado de aspectos necesarios para la concesión de las solicitudes de asilo y que, por tanto, podría incurrir en el no reconocimiento efectivo de derechos de diversos grupos de personas, entre las que se han de suponer las perseguidas por razón de su orientación sexual, e, incluso, en la expulsión posterior de las mismas a sus países de origen, violando el principio de no devolución consagrado en el convenio de Ginebra y el artículo 4 del protocolo del CEDH que prohíbe las expulsiones colectivas que muy probablemente vendrían a sucederse ante la ausencia de un análisis individualizado de las solicitudes (2016). Por último, en el recurso presentado ante el TJUE se 
acusa al acuerdo de suponer una desviación de poder por parte de las instituciones comunitarias al haber utilizado sus competencias "no en favor de los ciudadanos sino al servicio de sus intereses espurios con el gobierno turco" (Migraciones forzadas, 2016, p. 2). Por tanto, parece aquí palpable el freno al derecho al asilo y la condena a miles de personas a una vida en países de tránsito no segura y nociva para las personas homosexuales y bisexuales. Verbigracia, al hacer frente a dicha realidad, surgen casos tales como el del joven gay sirio Mohamed Sankari, atrapado en Estambul debido a la decisión política de las autoridades europeas, que tras ser víctima de amenazas y violación desaparecería y sería decapitado el verano del pasado año 2016 (Amnistía Internacional, 2016).

\subsection{Criterio de enmascaramiento (covering)}

Retornando a la sistematización de la problemática que aquí se persigue hacer frente, en segundo lugar, diversos autores han coincidido en denunciar la exigencia o requisito de enmascaramiento; es decir, el no reconocimiento del estatuto de refugiado motivado en la petición o exigencia de los agentes responsables del proceso de asilo para que la persona solicitante oculte su propia orientación sexual con el fin de evitar la persecución. Por tanto, se trataría aquí de un criterio que llama a ser un dispositivo transitado por las personas estigmatizadas que se hayan forzadas a enclaustrar su identidad ante terceros (Goffman, 1986). Valga recordar que dicho precepto, en clave de discreción, fue desestimado por el Tribunal Supremo del Reino Unido en el año 2010, arguyendo en su fallo que la discreción vendría a minar uno de los principios básicos del derecho de las personas refugiadas: que ninguna persona debe ser obligada a ocultar, cambiar o renunciar a la propia identidad con el fin de paliar el riesgo que las mismas padecen. En un mismo sentido, la meritada sentencia del TJUE del 7 de noviembre de 2013 rechaza el presente criterio de enmascaramiento al concebir que el hecho de que a los sujetos de un colectivo social se les requiera ocultar su orientación, resulta contrario al reconocimiento de una característica fundamental de la misma que imposibilita su renuncia (Tsuordi, 2016). De hecho, y pese a que, por temor a sufrir violencia, discriminación y exclusión, múltiples personas pudieran no desear expresar su verdadera orientación sexual, ello no implica en absoluto que se pueda sugerir, cuando no obligar, a la persona solicitante de asilo por dichos motivos a llevar una vida de acuerdo con una orientación sexual que no considere como propia (Díaz de la Fuente, 2016). Además, la exigencia de discreción se manifiesta contraria al principio de no discriminación establecido en el propio preámbulo de la Convención de Ginebra de 1951 que, debidamente, ha de inspirar a la interpretación y la gestión de la normativa internacional sobre el conjunto de las personas refugiadas. Por último, puede deducirse que tras el 
criterio de enmascaramiento vindicado aún por ciertas autoridades y jurisdicciones subyace la conjetura o suposición de que la orientación sexual no es sino un comportamiento optativo y discrecional que puede ser, arcanamente, vivido sin necesidad de vulnerar las directivas y estándares sociales de género imperantes en el país de origen.

No obstante, tal razonamiento continúa siendo esgrimido de facto, más no de iure, por múltiples Estados europeos. De acuerdo con el estudio de distintas valoraciones e informes especializados, tal requisito ha seguido siendo aplicado en Austria, máxime para las solicitudes de personas bisexuales, Bélgica, Bulgaria, Chipre, Dinamarca, Finlandia, Francia, Hungría, Irlanda, Malta, Países Bajos, Polonia y Rumania (Tsuordi, 2016). Esta situación ha venido agravándose en Europa Central y Oriental donde, a modo de ejemplo, la discreción ha terminado siendo una postura defendida tanto por la Oficina de Inmigración y Nacionalidad de Hungría como por la Oficina de Extranjería de Polonia ante solicitudes provenientes de Argelia y Pakistán, respectivamente (Śledzińska-Simon \& Śmiszek, 2016).

En todo caso, así como resulta inimaginable la exigencia de clandestinidad para con aquellas personas que pudieran estar siendo perseguidas por procesar una religión alternativa o que lo fueran por expresar opiniones políticas divergentes con el régimen autoritario o dictatorial del que forman parte, es sumamente reseñable que este requisito, cuya principal característica no es otra salvo limitar la vivencia y la expresión de los sujetos solicitantes, vulnerando así los derechos humanos al libre desarrollo de la personalidad, a la libertad y la igualdad, a la intimidad y a la integridad física y psicológica de la persona; únicamente esté viéndose aplicado bajo el supuesto de persecución por motivos de orientación sexual (Richard, 2016). A razón de ello, se advierten aquí las grietas homófobas del marco heteropatriarcal sobre el que actúa la política de asilo y refugio europea.

\subsection{Criterio de criminalización}

En un tercer lugar y prosiguiendo con la sistematización, la academia ha venido denunciando la criminalización o el fatídico destino de la población solicitante para cuando los cuerpos jurisdiccionales no reconocen como riesgo de persecución la mera existencia de leyes que tipifiquen como delito las relaciones entre personas del mismo sexo ni las consideren, por tanto, congruentes para el reconocimiento de la condición de refugiado (Türk, 2016). Flagrantemente, esta exigencia ha venido perpetrándose en el conjunto de los Estados de Europa Central y Oriental bajo el requerimiento del tipo delictual en el ordenamiento jurídico penal del país originario de la persona solicitante (Tsuordi, 2016). Parece así presumible que una crítica relativa a la regulación de la orientación sexual como 
motivo operable para con la obtención de asilo en los ordenamientos jurídicos europeos, verse en relación al supuesto de que tal integración ha sido efectuada de forma discriminatoria incidiendo en arduas restricciones que bien habrían de ser corregidas en un posterior tratamiento de la normativa comunitaria.

Holgadamente, el reconocimiento de la orientación sexual, adscrita al modelo de grupo social determinado, maniobra de forma exclusiva en función de las circunstancias imperantes en el Estado originario de la persona solicitante (Migraciones forzadas, 2016). Así pues, diversos Estados europeos, tales como la República Francesa, requieren y exigen tanto una reiterada aplicación de la ley punitiva por parte del país de origen, como el imperativo de que la propia persona solicitante corrobore las acciones dirigidas contra sí en su caso particular (Tsuordi, 2016). Es por ello que dicho requerimiento confirma un inequívoco supuesto de inseguridad jurídica para con las personas solicitantes de asilo por dichas motivaciones, en la medida que la ausencia de información sobre el país de origen por parte de las autoridades puede conllevar, prejuiciosamente, la no tramitación sistemática del exigido examen individualizado sobre las circunstancias personales del solicitante (Tsuordi, 2016). Como ha podido apreciarse en el caso kosovar, más allá del enfoque de una contingente pero potencial ejecución de la ley, dicha justificación desoye y rehúsa a advertir el grado de discriminación y exclusión en todos aquellos Estados que vienen a penalizar socioculturalmente la mera existencia de personas no heterosexuales. Además, y en relación a los otros motivos de persecución, esta restricción opera de forma discriminatoria frente a las identidades restantes tales como la nacionalidad, la raza, la religión u opinión política, sobre las que no procede la condición de circunstancias imperantes en el país de origen (Richard, 2016).

De este modo, parece posible extrapolar como la simple presencia de un régimen punitivo sancionador viabiliza que toda autoridad estatal pueda infligir daño grave contra las personas por su orientación sexual, y atenúa un ambiente permisivo con las violaciones de derechos humanos consumadas por agentes no estatales, en ambientes sociales o familiares, contra personas homosexuales y bisexuales (CEAR, 2016). Igualmente, la casuística impide de facto la posibilidad de solicitar protección ante agentes nacionales que, por imperativo legal, estarían viéndose obligados a perseguir, sancionar y condenar los mismos motivos por los que la persona perseguida solicita protección, incurriendo en uno de los supuestos de falta de protección interna contemplados (CEAR, 2016). Con todo, dicha postura jurisprudencial es asimismo contraria a la instituida por distintos tribunales de Estados comunitarios, como la jurisprudencia del Tribunal de Casación italiano y, por lo dispuesto, por el TJUE (CEAR, 2016). Valga señalar que la normativa de asilo europea aclara que "en ningún caso podrá entenderse la orientación sexual en un sentido que comporte actos considerados delictivos”, pauta patentemente 
redundante dado que la Directiva de reconocimiento ya preludia entre los supuestos de exclusión, ajustables al conjunto de motivos de persecución, la comisión de delitos graves comunes. Así pues, este mandato parece responder a un desconocimiento flagrante de la realidad sexual, conformando una deleznable irrupción del cuerpo legislativo en prejuicios discriminatorios que parecen ligar veladamente la orientación sexual con acciones tipificadas penalmente como lo son los delitos de agresión y acoso sexual, de exhibicionismo, y aquellos relativos al abuso, prostitución y corrupción de menores, sobre los que bajo ningún supuesto resulta pertinente la orientación sexual del sujeto perpetrador (Richard, 2016).

Por último, urge reprobar aquí los efectos de la conjunción "y" entre las características inmutables y la percepción social dentro de la Directiva 2011, que ha venido acarreando un obstáculo para las personas solicitantes a las que se ha venido demandando el cumplimiento de ambos elementos en vistas al reconocimiento efectivo de la protección o concesión estatutaria de la condición de persona refugiada (Tsuordi, 2016).

\subsection{Criterio de incredulidad}

En cuarto lugar, urge señalar aquí el criterio de incredulidad cuando en el procedimiento para la evaluación de la solicitud, ciertas jurisdicciones niegan la auto-identificación y exigen pruebas, testificaciones o documentos personales aclarativos, ya sean cartas, correos electrónicos o material fotográfico, sobre la verdadera identidad del sujeto. Como señalan Śledzińska-Simon y Śmiszek, la incredulidad supone una simplificación extrema de la realidad de las personas homosexuales y bisexuales solicitantes de asilo hasta la situación de negar o poner en entredicho el alegato de las mismas por haber tenido relaciones heterosexuales y descendencia fruto de las mismas (2016). Como ha sido tratado, ello implica ignorar la suma dificultad a la que la persona solicitante pudiera verse sometida para suministrar las pruebas, en particular, cuando en su vida previa bien pudiera haber hecho cuanto estuviera a su alcance para encubrir una orientación sexual que estaría encaminándola a la estigmatización, la exclusión o la muerte (Türk, 2016).

Sin embargo, resulta reseñable la nula credibilidad que se le ha venido concediendo al relato de las personas solicitantes de asilo por motivos de orientación sexual, pudiendo afirmarse, incluso, frente a la no aplicación en solicitudes fundamentadas en otras causas, la existencia de una presunción generalizada de abuso de derecho para con las personas que se dicen no heterosexuales (Richard, 2016). Sin fluctuación alguna, la desproporcionada demanda de pruebas que certifiquen la persecución razonada en la orientación sexual de la persona solicitante colisiona paradójicamente con el previamente disertado menester de enmascaramiento pretendido en múltiples jurisdicciones europeas (Türk, 2016). 
Además, Türk ha señalado cómo la orientación sexual, al carecer de la visibilidad que se le presupone a la raza y, en menor medida, a la etnia, religión o nacionalidad, ha llevado a las autoridades a basarse en la estereotipación para la obtención de pruebas que aclaren si el solicitante es, justamente, no heterosexual. Como es sabido, ante la falta de asesoramiento e información, en múltiples ocasiones, el funcionariado ha basado sus decisiones en sus propias especulaciones y prejuicios, minando así la imparcialidad y objetividad que se le presupone para con la toma de decisiones (2016). Así con todo, en Hungría, el hecho de no facilitar datos sobre las orientaciones no heterosexuales en la primera fase de solicitud continúa considerándose un elemento negativo para la evaluación (ŚledzińskaSimon \& Śmiszek, 2016). A raíz de lo expuesto, se evidencia aquí cómo "las prácticas reforzadas de los regímenes sexuales reguladores", del contrato de heterosexualidad obligatoria, instituyen los ideales, normatividades y perspectivas de todo aquello que resulte posible y realizable (Butler, 2002, p. 214).

Ligado a lo previo, diversos autores recogen el inmoderado y desatinado énfasis que ciertos agentes decisorios conceden a los actos sexuales frente a la orientación sexual cual hecho identitario de la persona solicitante, como dificultad para el reconocimiento efectivo del derecho que aquí compete. Como resulta deducible, ello no sólo conduce a un cuestionamiento invasivo, humillante y degradante de la vida sexual de la persona, sino que ignora el hecho de que las personas no heterosexuales tienden a ser reiteradamente perseguidas en tanto que su mera existencia encarna una amenaza para las costumbres socioculturales imperantes en sus países originarios (Türk, 2016). En pos de ello, es posible afirmar que los Estados europeos parten de una óptica etnocéntrica y esencialista con respecto a las identidades sexuales de las multitudes queer que confrontan la viabilidad de "las políticas universalistas que asientan el reconocimiento e imponen la integración de las diferencias en el seno de la República” (Preciado, 2010, p. 55).

Así pues, se ha venido advirtiendo cómo en algunos Estados miembros se opta para valorar la verosimilitud de la solicitud de asilo, por la práctica de un reconocimiento médico, psicológico o psiquiátrico que alcance, supuestamente, a determinar la orientación sexual (Migraciones forzadas, 2016). Se habla aquí de una batalla forense que devenga en demostrar la orientación sexual del solicitante mediante entrevistas "clínicas", de dudosa fiabilidad, que otorguen o denieguen la "identidad". En el peor de los casos y de acuerdo con una multiplicidad de informes, se sugiere aquí que las personas solicitantes de asilo que alegaran persecución motivada en su orientación sexual, estarían viéndose negadas cuando no condenadas a tratos inhumanos y degradantes, por parte de las autoridades a fin de confirmar la veracidad de su orientación, con serias consecuencias psicológicas, especialmente, entre aquellas que se hubieran visto obligadas a afrontar procesos análogos en sus Estados previos (Migraciones forzadas, 2016). Con todo 
ello, Amnistía Internacional ha denunciado que la denominada prueba médica es una violación de derechos humanos reclamando que no siga siendo empleada (2016). En la misma línea, el propio Tribunal de Justicia de la Unión Europea, en sentencia de 2 de diciembre de 2014, sobre los asuntos acumulados C-148 a C-150 de 2013, ha reverenciado que las personas solicitantes de asilo que aleguen riesgo de persecución en sus países de origen justificado en su orientación sexual, no pueden ser sometidas en los Estados miembros a minuciosos interrogatorios sobre sus prácticas sexuales para demostrarlo, puesto que ello atentaría contra sus derechos fundamentales (Tsuordi, 2016).

Sin embargo y a modo de ejemplo, entre los años 2012 y 2014, la República Checa llevó a cabo, y pese a su prohibición, evaluaciones "falométricas" -pletimografía peneana- que se basaban en una entrevista con un sexólogo; práctica harto injusta y contraria al marco normativo europeo (Śledzińska-Simon \& Śmiszek, 2016). Por su parte, aun dando término a la misma como reacción a las duras críticas de la Agencia de Derechos Fundamentales de la UE, en Eslovaquia todavía es requerido un dictamen pericial (Richard, 2016). Por último, las autoridades de asilo búlgaras someten a un duro interrogatorio de temas íntimos como las posiciones sexuales predilectas o el número de parejas sexuales (Śledzińska-Simon \& Śmiszek, 2016). Por lo tanto, en esta democracia identitaria y al incurrir en este criterio, se estaría optando por ignorar la existencia de persecución individualizada de las personas solicitantes, en aras a la esencialización de las mismas para el reconocimiento, efectivo o no, del derecho humano al asilo. Es decir, y siguiendo la advertencia de Rubin, parece asumible que los Estados europeos, guiados por un pánico moral o guerra sexual en forma de llegada masiva de personas refugiadas, no estarían sino extendido su poder "haciendo de los discursos sobre el sexo y de las tecnologías de normalización de las identidades sexuales un agente de control sobre la vida" (Preciado, 2010, p. 9); esto es, atando y enlazando las representaciones liberales de diversidad, en aras a acceder, a través de la supremacía de la blanquitud, a la explotación indómita de los propios sujetos que son incorporados a la biopolítica europea en una primera instancia (Chow, 2006).

\section{LA FORTALEZA ROSA DIALÉCTICA $\left(\mathrm{H}^{2}\right)$ : EL CRITERIO DE PRESUNCIÓN DE PLURALISMO}

Finalmente, y en vistas a la deriva autoritaria y perjudicial en el plano jurídico y sociopolítico para las personas homosexuales y bisexuales en distintos Estados miembros, se ha considerado aquí, en aras a proseguir con la falsación de la hipótesis secundaria, la incorporación de un quinto criterio o elemento problematizador para con el reconocimiento efectivo de la protección internacional. 
En síntesis, se acusa aquí a la presunción de pluralismo europeo de la obstrucción de acceso a refugio a las personas no heterosexuales de cual fuera el Estado comunitario. Por lo pronto, el rastreo arqueológico apunta y visualiza la historia de un pasado y aún presente europeo que ha conocido y perpetuado el despotismo y el fundamentalismo y las violaciones sistemáticas de derechos humanos, contribuyendo en gran medida a la universalización del ideario heteropatriarcal que mina las libertades de las personas que aquí ocupan el análisis (Dow, 2002).

En pos de ello, apremia cerciorar como la descripción etno-eurocéntrica de la tolerancia pluralista ante la permisividad afectivo-sexual como un principio y fin europeo contrapuesto a las realidades de otros contextos, camufla la discriminación homófoba actual e histórica de las sociedades europeas, donde actualmente Estados nacionales tales como Polonia y Hungría no han hecho sino ahondar en su homofobia institucional y social (Tsuordi, 2016), condenando a una multitud ciudadana homosexual y bisexual al exilio.

Ante esta tesitura, cabe arremeter contra un Protocolo Aznar que imposibilita la solicitud de asilo para unos sujetos comunitarios que revelan, mediante su persecución, la apócrifa aceptación de las personas homosexuales y bisexuales en múltiples estados europeos, visualizando asimismo una xenofobia que reconoce sólo a parte del viejo continente como civilizado frente a la barbarie exterior exclusiva a las fronteras europeas. Igualmente, huelga recoger aquí a modo de confirmación, tanto las estadísticas que desprenden las organizaciones LGBTI alemanas sobre las agresiones vertidas contra la población refugiada homosexual y bisexual berlinesa que, entre 2014 y 2016, llegaron a registrar más de 400 casos de embates físicos, insultos o amenazas contra la misma (Migraciones forzadas, 2016); como la inacción del Estado búlgaro ante la violencia perpetrada contra los manifestantes en el último Orgullo LGBTI (Amnistía Internacional, 2016).

A su vez, partiendo de Thomas Dye y asumiendo que una "política pública es todo aquello que el gobierno decide hacer o no hacer" (1976, p. 10), la inacción casi completa por parte de las instituciones europeas pertinentes en materia de inclusión social y no discriminación de las personas refugiadas no heterosexuales (Tsuordi, 2016), evidencia una falta de compromiso tácito para con unas multitudes queer incapaces de adquirir el estatus social de ciudadanía.

\section{ESPANA COMO FACTOR DE CONTROL (H): LAS VOCES QUE (NO) IMPORTAN}

En tanto que la interseccionalidad exige afrontar una dualidad analítica en razón de los efectos de las estructuras de exclusión social en los sistemas de organización y perpetuación macrosociológicos -interlocking systems of oppressiony de las derivaciones referidas a los procesos vitales individuales o fenómenos 
microsociológicos -intersectionality - (Hill Collins, 2000), se toma aquí a España como factor de control, en tanto que país con mayor tasa de aceptación de la homosexualidad (Alegre, 2017), en vistas a entrever la posible racialización de los cuerpos heterodisidentes tanto desde un análisis macro-documental jurisprudencial como micro-discursivo a través la entrevista focalizada.

Conviene comenzar aquí señalando la inquietud del investigador y el sesgo de su análisis ante un estudio discursivo que sólo alcanza a sistematizar cualitativamente y, por falta de medios, al conglomerado de cuerpos que vienen a atravesar la fortaleza europea y no así a las multitudes queer que son condenadas a ahogarse en su propio mediterráneo. Ante esta tesitura, resulta complejo identificar correctamente las tecnologías y los aparatos mediante los cuales los procesos de racialización conforman las axiomáticas distancias entre la vida y la muerte, la seguridad y la inseguridad y el derecho o la ausencia al refugio. Sin embargo y siguiendo a Stuart Hall, parece posible asumir que la identidad de los cuerpos queer que alcanzan a atravesar la fortaleza, adquiriendo así la condición de sujetos normativos excepcionales mediante la condición o estatuto de refugiado, se produce en relación a su alteridad; esto es, gracias al afuera constitutivo producido y racializado como extranjero de quienes aquí, en un principio, parecían sujetos excluidos del análisis (Hall, 2011). En este sentido, la voz de las personas entrevistadas, junto al análisis de fuentes secundarias, revela veladamente la existencia de quienes en esta investigación no han alcanzado a ser rescatadas: ese conjunto de personas no heterosexuales supuestamente incapaces de probar su situación y rechazadas por un sistema de asilo y refugio español en el que, abiertamente ahora sí, no importan.

Por lo pronto, cabe señalar como de acuerdo con los principios jurisprudenciales españoles sobre el derecho de asilo por motivos de orientación sexual, puede concluirse que, para la concesión a trámite de una solicitud de asilo, han de intervenir dos salvedades: un elemento positivo en clave de inexcusable descripción de una persecución por motivos de orientación sexual, conjunto a uno negativo constituido en la falta de ostensible falsedad o inverosimilitud. En consonancia e in dubio pro refugiado, el cuerpo administrativo asume la competencia de conferir las solicitudes a trámite en caso de duda para que el procedimiento ratifique una respuesta mediante el análisis casuístico individualizado que requiera al solicitante de la justificada acreditación de los hechos para estimar la autenticidad del relato (CEAR, 2016). Sin embargo, y partiendo de Foucault, en esta democracia identitaria, la sexualidad no aparece como aquello que los sujetos están obligados a callar, sino como aquello que los cuerpos humanos se ven obligados a confesar (1975). En otras palabras, las tres personas entrevistadas ${ }^{15}$ exponen haber partici-

${ }^{15}$ Para la realización de este trabajo se realizaron tres entrevistas cualitativas a solicitantes de asilo que, por razones de privacidad, mantienen su anonimato bajo la denominación de Anónimo 1, 2 y 3. 
pado, bajo el constante temor a ser deportadas, en un proceso sumamente largo y hastioso que definen como "una prueba a contrarreloj para demostrar que eres una cosa y que quieren matarte por ella" (Anónimo 1). En consecuencia, prevalece la óptica de la acusación permanente frente al in dubio pro-refugiado que habría de prevalecer acorde a la normativa europea y española, convirtiendo a las personas solicitantes en "sin papeles" (Anónimo 2): ilegales, criminales que carecen de derecho "a estar donde están y que han venido a robar el trabajo a los hijos" de la ciudadanía española, en palabras, supuestamente, de un agente policial (Anónimo 1). Como afirma Álvarez González, parece factible que el fundamento de tal exclusión encuentre su respuesta en la concepción de los derechos humanos como privilegios occidentales; escenario neoliberal amurallado, en gran medida, por una escasez material que induce a que decretados derechos se conciban como parte de una riqueza nacional que viene a vetar a aquellos ajenos a la comunidad (2006).

Por otro lado, si bien conviene subrayar el actual grado de sensibilidad y concienciación por parte de los agentes de asilo españoles, según datos ofrecidos por CEAR, parece posible afirmar que, de forma implícita, el enmascaramiento continúa siendo un requisito a fin de no considerar admisibles los riesgos de persecución que conducen a las personas a la solicitud (CEAR, 2016): "eso de que tuviera un hijo les hacía dudar (...) me dijeron que podía volver a otra parte del país lejos de mi familia y hacer mi vida con otra mujer. Volver a tener una vida normal" (Anónimo 1).

Igualmente, urge recordar aquí como el artículo 6 de la Ley de Asilo integra, entre los actos constitutivos de persecución, las medidas legales y administrativas discriminatorias en contraposición a la ya comentada problemática en torno a la criminalización. Por ello, las leyes que de forma directa o indirecta sancionen los actos sexuales entre personas del mismo sexo han de comprenderse per se constitutivas de un acto de persecución (Díaz de la Fuente, 2016). De hecho, la interpretación plasmada por tribunales españoles sobre la criminalización de los actos homosexuales en el país de origen ha sabido adecuarse a los estándares determinados por el TJUE que, en sentencia de 7 de noviembre de 2013, apreció la necesidad de la aplicación efectiva de la norma punitiva por ser constitutiva de acto de persecución, pero sin requerir su personificación o individualización sobre la persona solicitante de protección internacional (CEAR, 2016). Por tanto y sin ahondar en mayor profundidad, si bien los entrevistados no alcanzaron a encontrar en las autoridades públicas españolas minimización alguna en la situación de las personas homosexuales y bisexuales en sus países de origen -Marruecos, Yemen y Mauritania-, sí que afirman sentir minimizada su propia situación particular como método de control legítimo de flujos migratorios "no merecidos" (Anónimo 2): "es labor de las autoridades perseguir el fraude para que no entre nadie que no se lo merezca" (Anónimo 1). Tal es así que parece posible dilucidar 
los inicios de la transfiguración de las multitudes queer aquí presentes, en sujetos normativos excepcionales que vindican protección para los suyos y muerte indirecta para los otros.

En consonancia a lo previo, la incredulidad se manifiesta ferozmente en los tres discursos analizados: "tuve que superar un montón de pruebas y exámenes psicológicos aportando muchísimas pruebas de todo lo que me habían hecho y de lo que querían hacerme" (Anónimo 1), "me hicieron muchísimas preguntas de mi relato desde diferentes focos, pretendiendo, creo yo, confundirme y saber si mentía en algo" (Anónimo 2), "incluso me dijeron que era difícil verificar que los mensajes de las amenazas eran de verdad" (Anónimo 3). Tanto así, que, prosiguiendo con la lógica acusatoria, se afirma que a las autoridades públicas "no les bastaron los mensajes amenazantes de mi familia y de gente del pueblo, las cicatrices en el cuerpo ni la prueba médica que demostró que me habían violado correctivamente" (Anónimo 1), ni tampoco las "cartas" ni "resguardos de la Administración penitenciaria en las que se solicitaba audiencia con mi novio retenido" que "de nada sirvieron" (Anónimo 2). Así, las personas entrevistadas sostienen la exigencia de pruebas materiales de "carácter persecutorio" de difícil alcance: "me pidieron fotos, pero no pude enseñar ninguna en que apareciera con mi novio besándonos, porque era peligroso tener algo así en Yemen" (Anónimo 2), y que ignoran conscientemente o no la realidad de los países de origen: "se me dijo que había muchos candidatos que pretendían engañar a las autoridades españolas con ese argumento. Algo imposible si se piensa en el deshonor que supone para cualquier yemení ser homosexual" (Anónimo 2). En definitiva, todo ello se traduce en un trato inhumano y degradante, en una violación específica de los derechos humanos, que reclama la probación de la orientación sexual con consecuencias concretas para sujetos que se debaten entre la delgada línea entre la excepcionalidad y la muerte: "acabé con el ánimo por los suelos e incluso pensé en matarme para acabar ya de una vez por todas con lo que nadie quería. Ni aquí ni allí ni en ninguna parte" (Anónimo 1); "me pedían muchas pruebas de que mi vida corría peligro y me angustié... No podía volver allí y la idea de hacerlo me atormentaba tanto que me mareé" (Anónimo 3). A este respecto y siguiendo recientes sentencias que posibilitan la admisión del derecho de asilo aun a falta de indicios suficientes, Díaz de la Fuente considera que en consecuencia de la dificultad existente para con la probación de la orientación sexual y de su persecución consecuente, parecería comprensible un convenio más flexible, una vez y cuando el relato fuera preciso, detallado y coherente (2016).

En todo caso, de acuerdo con el artículo 13 del CEDH y con la jurisprudencia del TEDH, se imposibilita la devolución de la persona solicitante a su país de origen siempre que la Audiencia Nacional no haya emitido veredicto alguno sobre el fondo del recurso (Gortázar, 2017). Al respecto, la posible violación 
de este derecho efectivo fue el fundamento jurídico para que el 27 de marzo de 2015 el TEDH aceptara a trámite la demanda n..$^{\circ}$ 15109/15 sobre el asunto M.B. contra España e instara a las autoridades nacionales españolas, en virtud del artículo 39 del Reglamento del Tribunal, a la suspensión de la devolución de la demandante de asilo por su orientación sexual a su país de origen hasta que la Audiencia Nacional dictara sentencia sobre el recurso contra la inadmisibilidad de la demanda de protección internacional (CEAR, 2016). Igualmente, conviene traer a colación la sentencia de 22 de abril de 2014 sobre el asunto A.C. y otros contra España, por el que el Tribunal de Estrasburgo condenara a dicho Estado al no amparar el recurso efectivo y objetar las medidas cautelares tras la desestimación de la solicitud de asilo previo a la resolución del recurso ante la Audiencia Nacional (Amnistía Internacional, 2016). Además, en el año 2015 destaca el caso de la camerunesa Christelle Nangnou, retenida durante 24 días en el Aeropuerto de Barajas por la Guardia Civil que, en sus tres intentos por expulsarla al no considerar convincente su testimonio, terminaría generándole lesiones físicas y psicológicas aún y cuando su vida corría peligro al haberse visto publicados fotogramas que la señalaban como lesbiana en diversos medios periodísticos (Amnistía Internacional, 2016).

Asimismo, y si bien el criterio de incredulidad se vislumbra también, cuidadosa y veladamente, mediante la sexualización; "no me dijeron que me besara con otro hombre ni nada de eso (risas), pero sí que me preguntaron por hombres con los que yo hubiera estado en Santa Cruz..." (Anónimo 1); "sí, me preguntaron si había tenido experiencias con hombres, y cosas íntimas que no quise contestar porque me sentí atacada..."; es la estereotipación como forma de incredulidad lo que se considera merecedor aquí de una mayor atención. En palabras del cuerpo entrevistado: "creo que uno de los policías le dijo a su compañero que era muy femenina para ser lesbiana, eso creí entender, porque entonces mi español era muy básico..." (Anónimo 3); "les parecía demasiado masculino y varonil para estar con hombres... (Anónimo 1). A raíz del mismo, se evidencia una vez más cómo "las prácticas reforzadas de los regímenes sexuales reguladores", del contrato de heterosexualidad obligatoria, impiden la elección libre y voluntaria de las identidades, formando las ideas, normas y visiones de todo lo que resulta posible y realizable (Butler, 2002, p. 214). En pos de ello, el cuerpo funcionarial parte de una óptica etnocéntrica con respecto a las identidades sexuales de la otredad no heterosexual árabe y migrada que confronta la viabilidad de "las políticas universalistas que asientan el reconocimiento e imponen la integración de las diferencias en el seno de la República" (Preciado, 2010, p. 55); pues, en su dialéctica, refleja como "ningún sistema de clasificación puede catalogar o explicar de forma satisfactoria los infinitos caprichos de la diversidad humana" (Rubin, 2008, p. 30): "yo no sabía lo que era ser bisexual. Eso no se dice en mi país. No conocía la palabra y ellos tampoco me la dijeron hasta que la abogada me la dijo". En pos de 
esto último, las ONG no parecen actuar exclusivamente como defensoras de las personas refugiadas, sino que ejercen un rol mediador entre la Europa fortaleza y las multitudes queer en aras a que éstas últimas puedan ser filtradas por la primera mediante la reconfiguración de sus identidades. En definitiva y sin ellas, ni las autoridades ni las propias personas entrevistadas sabrían "exactamente qué hacer ante lo que les estaba planteando" (Anónimo 2); "porque en realidad les costó mucho entender mi situación" (Anónimo 3):

"Llame a ese sujeto excéntrico no sólo en el sentido de que se desvió de la senda normativa, convencional, sino también excéntrico en el sentido de que no está el mismo centrado en la institución de la heterosexualidad. De hecho, la institución no parecía tal sujeto y no lo podría considerar, no podría imaginarlo" (Butler, 2002, p. 147).

Es más, tal y como se ha venido a señalar, debido al advenimiento contemporáneo de sujetos homosexuales y bisexuales normativo, resulta ineluctable la configuración de una homonormatividad histórica y estratégica como medio por el cual el heterosexismo se relaciona con matrices alternativas o emergentes, incorporando nuevas realidades que transponen performativamente los horizontes de oportunidad (Moreno Sánchez \& Pichardo Galán, 2006) que sostienen copiosamente la administración de la vida (Ahmad, 2002). Por lo tanto, se demuestra aquí que el derecho a la existencia no es incondicional, pues desposee al cuerpo no heterosexual de humanidad supeditándolo a su situación racial mediante un contrato, entre la Europa fortaleza y las periferias afectivo-sexuales, en clave de promesa de protección para los suyos y de muerte para los otros.

\section{PRESENTACIÓN Y RECAPITULACIÓN DE RESULTADOS}

"Juzga más al hombre por sus preguntas que por sus respuestas"

\section{Voltaire}

A lo largo del presente trabajo de investigación, se ha perseguido ejecutar una investigación social cualitativa y descriptiva-documental, inter- y multidisciplinar en tanto que politológica, sociológica y jurídica, y bajo una perspectiva o enfoque interseccional, mediante la que resultase posible desarrollar, en un primer momento, un esfuerzo arqueológico que rastrease e incidiese en la configuración teórica y jurídica del espacio de cotidianidad sobre el que se trenza la realidad de una fortaleza europea que emerge, en parte, debido a su política migratoria de asilo y refugio en general, y con motivación en la orientación sexual en particular. Posteriormente, se han alcanzado a reflejar y analizarlas distintas problemáticas colectivas que pudieran coexistir imposibilitado tanto a las personas perseguidas 
por razón de su orientación sexual ejercer su derecho humano a la protección internacional, como a los Estados a cumplir con sus compromisos internacionales, europeos y constitucionales de promover, proteger y garantizar el ejercicio de todos los derechos humanos, incluidos, entre ellos, el derecho de asilo en su sentido más holístico.

En resumen, se ha alcanzado a corroborar como la asociación de la homofobia con la inmigración, el asilo y el refugio, no sólo ha venido a gestar una política homonacionalista que brota como una instrumentalización de la ciudadanía no heterosexual y la homofobia que ésta padece en aras a legitimar la xenofobia de la que emerge la fortaleza rosa europea, sino que invisibiliza la segregación, exclusión o exterminio a la que somete a la otredad heterodisidente que anhela refugio dentro de la Unión Europea. Así pues, este estudio coincide con la hipótesis principal de partida que proclamaba el carácter racializado de la fortaleza europea por el que el derecho humano a la vida o a la existencia de las personas homosexuales y bisexuales no es incondicional, pues depende de la situación nacional-administrativa de las mismas. Por tanto, la legitimación de las personas homosexuales y bisexuales como minoría normalizada no debe ser aprehendida como una victoria, sino como una consolidación del régimen social que reproduce, mediante una homonormatividad estratégica por la cual el heterosexismo se relaciona, las dominaciones, jerarquías y exclusiones sobre los cuerpos que no importan.

A modo sintético, la triangulación del estudio permite garantizar la verificación de la hipótesis descriptiva de acuerdo con los siguientes parámetros:

- Bajo el presente paradigma huntingtoniano y amparados en un pánico moral de naturaleza sexual -guerra o imperio sexual-, una multitud de dirigentes europeos ha venido a justificar sus políticas racistas y xenófobas con las personas refugiadas y migrantes como un instrumento que preserve los derechos de las personas homosexuales y bisexuales nacidas en el seno de la Unión Europea. No obstante, como se ha demostrado, estos mismos líderes políticos salvaguardan un silencio cómplice con las multitudes queer venidas de fuera, orientando con suma vehemencia una política de asilo y refugio que dificulta que las personas perseguidas, incluidas aquellas por motivación de orientación sexual, puedan solicitar asilo o encontrar refugio dentro de la Unión Europea.

- Resulta posible elucidar cómo la legislación europea en materia de asilo y refugio ha conocido un desarrollo progresivo que, pese a todo, mantiene tanto aplicaciones divergentes en sus distintas jurisdicciones como fallas para el reconocimiento efectivo del mismo derecho. Por tanto, a partir del estudio crítico de la jurisprudencia producida en los años en los que cabría esperar el auge de un homonacionalismo que brotase como un pánico moral 
derivado de la denominada crisis de refugiados, se han identificado cuatro criterios problematizadores para con los solicitantes de asilo y refugio no heterosexuales; a saber, invisibilización, enmascaramiento, criminalización e incredulidad:

o Invisibilización: se certifica la omisión de protección de múltiples multitudes queer solicitantes de asilo, en pos de la dogmática neoliberal. Así y según se ha venido punteando, desde la designada crisis de refugiados y a través de una mirada holística sobre la realidad de dicha gestión, la propia política de asilo y refugio ha venido a gestarse hondamente embebida por una cosmovisión sumamente economicista y basada en el control de flujos, y no tanto en los aspectos humanitarios y de desarrollo que jurídicamente debieran guiarla.

- Verbigracia, la pretensión de incorporar a la lista común de países seguros Estados que no lo son para las personas homosexuales y bisexuales, como Turquía o Kósovo, acentúa la posibilidad de que las mismas vean agravadas las dificultades iniciales para ver reconocido su derecho a la protección internacional.

- Por otro lado, se ha cerciorado que políticas exteriores y migratorias de la Unión Europea poseen consecuencias directas sobre las vidas de las personas no heterosexuales en terceros Estados. Así y a través de una medida como el Acuerdo UE-Turquía, se ha contemplado el freno al derecho al asilo y la condena a miles de personas a una vida no segura en países de tránsito para las personas homosexuales y bisexuales.

o Enmascaramiento: se evidencia casuística variada que recoge el no reconocimiento del estatuto de refugiado motivado en la petición o exigencia de los agentes responsables del proceso de asilo para que la persona solicitante oculte su propia orientación sexual con el fin de evitar la persecución. A razón de ello, se advierten aquí las grietas homófobas del marco heteropatriarcal sobre el que actúa la política de asilo y refugio europea.

- De acuerdo con el estudio de distintas valoraciones e informes especializados, tal requisito ha seguido siendo aplicado en Austria, máxime para las solicitudes de personas bisexuales, Bélgica, Bulgaria, Chipre, Dinamarca, Finlandia, Francia, Hungría, Irlanda, Malta, Países Bajos, Polonia y Rumanía. Además, de los testimonios arrojados en la entrevista, parece posible detectar un cierto uso de este criterio por parte de las autoridades españolas.

o Criminalización: se ha vislumbrado el fatídico destino de la población solicitante para cuando los cuerpos jurisdiccionales no reconocen como riesgo de persecución la mera existencia de leyes que tipifiquen como delito las relaciones entre personas del mismo sexo ni las consideren, 
por tanto, congruentes para el reconocimiento de la condición de refugiado.

- Huelga señalar aquí los efectos de la conjunción "y” entre las características inmutables y la percepción social dentro de la Directiva 2011, que ha venido acarreando un obstáculo para las personas solicitantes a las que se ha venido demandando el cumplimiento de ambos elementos en vistas al reconocimiento efectivo de la protección o concesión estatutaria de la condición de persona refugiada.

- Además, y en relación a los otros motivos de persecución, esta restricción opera de forma discriminatoria frente a las identidades restantes tales como la nacionalidad, la raza, la religión u opinión política, sobre las que no procede la condición de circunstancias imperantes en el país de origen.

o Incredulidad: se vislumbran las elevadas posibilidades que poseen los solicitantes de asilo que aleguen el motivo de su persecución en su orientación sexual, para verse negados cuando no condenados a tratos inhumanos y degradantes por parte de las autoridades a fin de confirmar la veracidad de su orientación.

- Por lo tanto, en esta democracia identitaria y al incurrir en este criterio, se opta por ignorar la existencia de persecución individualizada de las personas solicitantes, en aras a la esencialización; esto es, a la racialización de las mismas para el reconocimiento, efectivo o no, del derecho humano al asilo.

- La toma de España como factor de control y, muy especialmente, del uso de la entrevista focalizada, ha resultado de suma utilidad como herramienta analítica para con el estudio de procesos identitarios insertos en regímenes disciplinarios de los que parten las personas no heterosexuales refugiadas, y a los que sincrónicamente dan forma y contenido, en el marco de un sistema que no las admite si no es mediante su filtración republicana y universalista. En este sentido, se han encontrado indicios de enmascaramiento e incredulidad que vendrían a ratificar la hipótesis principal.

De esta primera hipótesis, se ha desprendido otro supuesto que, debido a la limitación temporal y espacial del investigador, sólo ha alcanzado a ser presentado y parcialmente comprobado en clave de hipótesis secundaria. Así pues, del análisis de la propia situación de ciudadanía de las personas homosexuales y bisexuales dentro de la Unión Europea -esto es, la presunción de pluralismo de la misma- desde una mirada focalizada en la política de asilo y refugio, se ha demostrado como la descripción etno-eurocéntrica de la tolerancia pluralista ante la permisividad afectivo-sexual como un principio y fin europeo contrapuesto a las realidades de otros contextos, 
invisibiliza la discriminación homófoba actual e histórica de las sociedades europeas, y es hondamente xenófoba al reconocer sólo a parte del viejo continente como civilizado frente a la barbarie exterior exclusiva a las fronteras europeas.

- Por ello, se ha hecho hincapié en la necesidad de revisar el Protocolo Aznar, pues obstruye el acceso a refugio de, entre otras, las personas no heterosexuales procedentes de cual fuera su Estado comunitario.

\section{CONCLUSIONES Y LIMITACIONES}

"Un texto escrito por un escritor minoritario sólo es efectivo si logra convertir en universal ese punto de vista minoritario".

Monique Wittig (1992, p. 85)

Como señalara Jon Elster, las ciencias sociales pueden aislar tendencias, propensiones y mecanismos, demostrando que tienen consecuencias para la conducta que, a menudo, son sorprendentes y contrarias a la intuición (1996). En este sentido, las palabras que preceden partían de la laboriosa y compleja tarea de analizar y dar respuesta a un fenómeno sociopolítico que, fruto de su originalidad, complejidad e invisibilización, carecía de una suma considerable de fuentes para su análisis. Por lo mismo, se asume que los resultados arrojados requieren de una mayor profundización que aquí el formato no permitía, si bien se espera que mediante la misma se pueda profundizar en el construir humano y colectivo que es la ciencia. En este sentido, "Desmontando la fortaleza (rosa) europea" apela al anhelo de desarrollar estrategias políticas reactivas que, en una modesta contribución al mandato de Spivak, produzcan "reordenamientos de deseos no coercitivos" (1985, p. 127). Se ruega aquí que este modesto estudio estimule nuevos interrogantes y más disyuntivas de los que necesariamente resuelve; que origine discusión en lugar de instalarse como una enseñanza magistral, exacta y prescriptiva.

No obstante, y pese a la verificación de la hipótesis principal, conviene realizar ciertas matizaciones a las proposiciones de partida:

- Los resultados obtenidos no parecen ser suficientes para cerciorar la verificación o falsación de una hipótesis secundaria que sostenía como los discursos y políticas homonacionalistas, al ser una estrategia del heterosexismo, esconderían la homofobia que se vendría produciendo en y desde la Unión Europea, desvelando dialécticamente el carácter pasajero de la excepcionalidad de la democracia sexual y del consenso para el reconocimiento y la incorporación de los cuerpos homosexuales y bisexuales nacionales. Por 
ello, se espera que esta aproximación sirva para un estudio en profundidad sobre dicha cuestión.

- Por tanto, al estar ante el advenimiento de la fortaleza rosa europea mediante una autoexplotación de los cuerpos homosexuales y bisexuales nacionales crecientes, los resultados ofrecidos sólo son una muestra de lo que podría estar por llegar ante el auge de las extremas derechas populistas europeas. En este sentido y bajo la advertencia de Rubin, urge recordar cómo una vez el furor del pánico moral sobre el que emerge la fortaleza europea culmine, cabría esperar que algún grupo sexual desafortunado se vea oprimido y el Estado extienda su poder "haciendo de los discursos sobre el sexo y de las tecnologías de normalización de las identidades sexuales un agente de control sobre la vida" (Preciado, 2010, p. 9).

- Conviene señalar la inquietud del investigador y el sesgo de su análisis ante un estudio discursivo que sólo alcanza a sistematizar cualitativamente y, por falta de medios, al conglomerado de cuerpos que vienen a atravesar la fortaleza europea y no así a las multitudes queer que son condenadas a ahogarse en su propio mediterráneo. Ante esta tesitura, resulta complejo identificar correctamente las tecnologías y los aparatos mediante los cuales los procesos de racialización conforman las axiomáticas distancias entre la vida y la muerte, la seguridad y la inseguridad y el derecho o la ausencia al refugio.

En definitiva, a un año del World Pride que acontece al investigador al escribir estas últimas palabras, él mismo pretende recordar cómo el 28 de junio no surgió como una mera vindicación identitaria, sino como el orgullo a defender el derecho a existir sin ser perseguidas; como el grito de guerra de una sociedad crítica y republicana que celebra un mundo diverso en el que todas las personas merecen respeto y las mismas oportunidades. Como señalaría María Zambrano, si bien hay cosas que no pueden decirse, son esas mismas las que deben ser escritas. Se espera que este trabajo sirva para movilizar a una sociedad civil que debe despertar para el mejor de los porvenires: el de la ciudadanía plural, formada y comprometida con la consecución de un mundo más libre e igualitario; con la construcción de una Europa que no deje atrás a nadie. 


\section{BIBLIOGRAFÍA}

\section{OBRAS DOCTRINALES}

Agamben, G. (1998). Home Sacer: Sovereign Power and Bare Life. Stanford: Stanford University Press.

Ahmad, M. (2002). Homeland Insecurity: Racial Violence the Day after September 11. Social Text 20, 72(3), 101-105.

Alegre, L. (2017). Elogio a la homosexualidad. Madrid: Arpa.

Alexander, M. J (1996). Erotic Autonomy as Politics of Decolonization: An Anatomy Feminist and State Practice, Feminists Genealogies, Colonial Legacies, Democratic Futures. Nueva York: Routledge.

Alguacil, J. et al. (2014). Cuaderno Metodológico de Trabajo de Fin de Grado en Sociología. Madrid: Universidad Carlos III.

Álvarez González, S. (2006). ¿Derechos fundamentals o derechos de ciudadanía? Algunas notas sobre la noción de ciudadanía. En Campoy Cervera, I. (ed.), Una discusión sobre la universalidad de los derechos humanos y la inmigración (pp. 195-204). Madrid: Dykinson.

Anzaldúa, G. (1987). Borders/Frontera. Madrid: Aunt Lute Books.

Atwood, M. (1986). El cuento de la criada. Madrid: Salamandra.

Bell Hooks, G. (1982). All the Women Are White, All Blacks are Men, But Some of Us are Brave. Nueva York: The Feminist Press.

Braudillard, J. (2005), The Mind of Terrorism. Steinmatte: The European Graduate School: Steinmatte

Bourdieu, P. (2000). La dominación masculina. Madrid: Anagrama.

Brah A. \& Phoenix A. (2004). Ain't I A Woman? Revisiting Intersectionality. Journal of International Women Studies, 5(3), 75-86.

Brown, B. (2005). The Dark Wood of Postmodernity (Space, Faith, Allegory). PLMA, 120(3), 734-750.

Buchanan, W. (2006). Broad Opposition to World Pride in Jerusalem. Berkeley: University of California Press.

Burke, P. (2000). History and Social Theory. Madrid: Amorrortu.

Butler, J. (2002). Global Violence, Sexual Politics. En GLAGS (ed.), Queer Ideas: The David R. Kessler Lectures Lesbian and Gay Studies (pp. 194-214). Nueva York: Feminist Press City University of New York.

Campbell, N. D. (2004). Techologies of Suspicion: Coercion and Compassion in Post. Disciplinary Surveillance Regimes. Surveillance and Society, 2(1), 78-92. Disponible en: http://www.surveillance-and-society.org Última consulta: 06/07/18

Cantú, Jr. (2005). Queer Migrations: Sexuality, U.S. Citizenship, and Border Crossings. Minneapolis: University of Minnesota Press. 
Chow, R. (2006). The Age of the World Target: Self-Referentiality in War, Theory, and Comparative Work. Durham: Duke University Press.

Cohen, S. (1980). Folk Devils and Moral Panics: The Creation of the Mods and Rockers, Oxford: Martin Robertson.

Crenshaw, K. W. (1989). Mapping the Margins: Intersectionality, Identity Politics, and Violence against Women of Color. Stanford Law Review, 43(6), 1.246-1.299.

De Lucas, J. (2006). Algunas tesis sobre el desafío que plantean los actuales flujos migratorios a la universalidad de los derechos humanos. En Campoy Cervera, I. (ed.), Una discusión sobre la universalidad de los derechos humanos y la inmigración (pp. 59-128). Madrid: Dykinson.

Despentes, V. (2006). Teoría King Kong. Barcelona: Melusina.

Díaz de la Fuente, J. (2016). Huir para amar: el derecho de asilo por motivos de orientación sexual e identidad de género. Valencia: Universidad de Valencia.

Duggan, L. (2004). Beyond Blood. Center for Lesbian and Gay Studies, GLAGS, Newsletter, 11(3) 1-2.

Dye, T. (1976). Policy analysis: what governments do, why they do it, and what difference it makes. Alabama: University of Alabama Press.

Edelman, L. (2004). No Future: Queer Theory and the Death Drive. Durham: Duke University Press.

Elster, J. (1996). Rationality and the Emotions. The economic Journal, 106, 1386-1397.

Eng, D. L \& Shinhee H. (2000). A Dialogue on Racial Melancholia. Pyschoanalytic Dialogues 10(4), 667-700.

Fassin, É. (2016). L'inversion de la question homosexuelle. Amsterdam: Poches.

Fauchier, A. (2016), Kósovo: iqué futuro le espera a las personas LGBT?, Migraciones Forzadas, 42, 36-39.

Fein, H. (1993). Genocide: A Sociological Perspective. Madrid: SAGE Publications.

Ferguson, R. (2003). Aberrations in Black: Towards a Queer of Color Critique. Minneapolis: University of Minnesota Press.

Fial-Matta, L. (2002). A Queer Mother for the Nation: The State and Gabriela Mistral. Minneapolis: University of Minnesota Press.

Firestone, K. (1970). The Dialectic of Sex: The Case for Feminist Revolution. Nueva York: William Morrow and Company.

Geertz, C. (1977). The Interpretation Of Cultures. Madrid: Aunt Lute Books.

Goffman, I. (1986). Estigma: la identidad deteriorada. Buenos Aires: Amorrortu.

Gortázar, C. (1997). Derecho de asilo y no rechazo del refugiado. Madrid; Dykinson-Universidad Pontificia Comillas.

Gortázar, C. (2016). ¿Cómo gestionar las solicitudes de asilo en Europa de manera razonable y acorde a derecho? Madrid: Universidad Pontificia de Comillas.

Gramsci, A. (1948). El materialismo histórico y la filosofía de Benedetto Croce. Buenos Aires: Nueva Visión Argentina. 
Guasch, O. (1995). La sociedad rosa. Madrid: Anagrama.

Guillaumin, C. (1992). Sexe, Race et Pratique du pouvoir. L'idée de Nature. París: Côté-femmes.

Han, B. (2012). La sociedad del cansancio. Barcelona: Herder.

Han, B. (2013). La sociedad de la transparencia. Barcelona: Herder.

Haraway, D. (1991). Manifiesto para ciborgs: ciencia, tecnología y feminismo socialista a finales del siglo XX. La reinvención de la naturaleza. Madrid: Cátedra.

Harding, S. (1987). Feminism and Methodology: Social Science Issues. Los Ángeles: UCLA.

Hill Collins (2000). Black Feminist Thought: Knowledge, Consciousness, and the Politics of Empowerment. Washington: Psychology Press.

Huntington, S. P. (2006). El choque de civilizaciones. Madrid: Paidós.

Institute Allenbach (2016). Passauer Neue Presse. Berlín: Universidad Libre de Berlín.

Kaplan, A. (2004). Violent Belongings and the Question of Empire Today: Presidential Address to the American Studies Association. American Quarterly, $56(1), 1-18$.

Martínez Reguera, E. (1988). Cachorros de nadie. Madrid: Paidós.

Marx, K. y Engels, F. (1845). El capital, Volumen 1. Madrid: Paidós.

Matsuda, M. (1991). Critical race theory, race and gender microaggressions. Legal Theory Out of Coalition. Stanford Law Review, 43.

McCall, L. (2005). The Complexity of Intersectionality. Journal of Women, Culture, and Society, 30(3), 1.771-1800.

McClintock, A. (1995). Imperial Leather: Race, Gender, and Sexuality. Nueva York: Routledge.

McWhorter, L. (2003). Sex, Race, and Biopower: a foucauldian genealogy. Hypatia: a Journal of Feminist Philosophy, 19(3), 38-62.

Pateman, C. (1988),. El contrato sexual. Madrid: Anthropos.

Patton, C. (2000). Queer Diasporas. Durham: Duke University Press.

Peces-Barba, G. (1995). Curso de derechos fundamentales. Madrid: BOE.

Peterson, V. S. (1999). Sexing Political Identities: Nationalism as heterosexism. International Feminist Journal of Politics, 1(1), 34-65.

Phelan, J. C. (2001). Conceptualizing Stigma. Annual Review of Sociology, 27, 363-385.

Platero, R. L. (2012). Intersecciones: cuerpos y sexualidades en la encrucijada. Temas contemporáneos. Barcelona: Bellaterra.

Preciado, P. (2010). The pharmaco-pornographic regime: sex, gender, and subjectivity in the age of punk capitalism. En Stryker, S. \& Aizura, A. Z. (eds.), The Transgender Studies Reader 2. Nueva York: Routledge.

Puar, J. K. (2017). Terrorist Assemblages: homonationalism in queer times. Barcelona: Edicions Bellaterra. 
Rey Pérez, J. L. (2006). Identidad e inmigración (o la lucha contra la inmigración como actividad estatal de supervivencia). En Campoy Cervera, I. (ed.), Una discusión sobre la universalidad de los derechos humanos y la inmigración (pp. 271282). Madrid: Dykinson.

Richard, A. C. (2013). LGBT: con el mismo derecho a los derechos humanos y la dignidad. Migraciones Forzosas, 42, 4.

Rodríguez Carrión, A. J. (2007). Lecciones de derecho internacional público. Tecnos: Madrid.

Rubin, G. (1989). Reflexionando sobre el sexo: notas para una teoría radical de la sexualidad. Minneapolis: University of Minnesota Press.

Ruggie, J. G. (1975). International Regimes, Transactions, and Change: Embedded Liberalism in the Postwar Economic Order. International Organization, 36, 379-415.

Said, E. (1988). The Essential Terrorist, Blaming the Victims: spurius Scholarsh the Plaestine Question. Nueva York: Verso.

Śledzińska-Simon, A. \& Śmiszek, K. (2016), Solicitudes de asilo de personas LGBTI - la perspectiva de Europa Central y Oriental, Migraciones Forzosas, 42, 16-18.

Speed, J. (2006). Science to change the world. Steinmatte: The European Graduate School.

Spivak, G. C. (1985). Can the Subaltern Speak, Speculations on Widow Sacrifice. Steinmatte: The European Graduate School.

Stuart Hall, (2011). The neoliberal revolution. Londres: Stuart Hall Library.

Trujillo Herrera, R. (2003). La Unión Europea y el derecho de asilo. Madrid; Dykinson.

Tsuordi, E. (2013). Orientación sexual e identidad de género: avances en la legislación de la UE en materia de asilo, Migraciones Forzosas, 42, 20-21.

Türk, V. (2013). Garantizar la protección para las personas refugiadas de Interés LGBTI, Migraciones Forzosas, 42, 5-8.

Valles, M. S. (2009). Técnicas de Investigación Social. Madrid: Síntesis.

Volpp, L. (2002). The Citizen and the Terrorist. UCLA Law Review 49(5), 157-160.

Wendt, A. (1999). Social Theory of International Politics. Nueva York: Routledge.

Wittig, M. (1992). El pensamiento heterosexual. Madrid: Egales.

\section{PUBLICACIONES ELECTRÓNICAS}

Amnistía Internacional (2016), Informe anual 2016/2017. Disponible en: https:// www.es.amnesty.org/en-que-estamos/informe-anual/?pk_campaign=anunggl\&pk_kwd=informe_informeanual17_1 Última consulta: 06/07/18.

BBC (2015), Cómo la religión se metió de lleno en el debate sobre la crisis migratoria de Europa. BBC Mundo. 15 de septiembre. Disponible en: http://www.bbc.com/ 
mundo/noticias/2015/09/150904_crisis_migratoria_europa_debate_islam_ musulmanes_religion_hungria_paises_este_lv_sd Última consulta: 06/07/18.

BBC (2016), El islam es incompatible con Occidente. BBC Mundo. 4 de febrero. Disponible en: http://www.bbc.com/mundo/noticias/2015/09/150904_el_islam_incompatible_occidente Última consulta: 06/07/18.

CEAR (2016), Informe 2016: las personas refugiadas en España y en Europa. Disponible en: https://www.cear.es/wpcontent/uploads/2016/06/Informe_CEAR_ 2016.pdf Última consulta: 06/07/18.

Comisión Europea (2016), Comunicación de la Comisión al Parlamento europeo y al Consejo: hacia una reforma del Sistema Europeo Común de Asilo y una mejora de las vías legales a Europa, Comunicado de prensa. Disponible en: https://ec.europa.eu/transparency/regdoc/rep/1/2016/ES/1-2016-197-ES-F1-1.PDF

Comisión Europea (2016), Hacia un sistema europeo común de asilo, equitativo y sostenible, Comunicado de prensa. Disponible en: http://europa.eu/rapid/pressrelease_IP-16-1620_es.htm Ultima consulta: 06/07/18.

Comisión Europea (2017), La lista común a la UE de países de origen seguros. Asuntos Interiores. Disponible en: https://ec.europa.eu/home-affairs/sites/homeaffairs/ files/what-we-do/policies/european-agenda-migration/background-information/docs/2_eu_safe_countries_of_origin_es.pdf Última consulta: 06/07/18.

Dow, M. (2002), The New Secret War against Immigrants, Gotham Gazette, 30 de enero. Disponible en: http://www.gothamgazette.com Última consulta: 06/07/18 France 2(2017), Replay integral. "2017, le debat": Marine Le Pen - Emmanuel Macron. Youtube. Disponible en: https://www.youtube.com/watch?v=i5aqL7FBxyI Última consulta: 06/07/18.

Furahashi, Y. (2004), A Clash of Civilizations, Sending Pink Sparks flying?, Critical Montages, 8 de Junio. Disponible en: http://montages.blogspot.com Última consulta: 06/07/18.

Gortázar, C. (2016, 16 de marzo), Sin que a la bella, culta y civilizada Europa se le altere el gesto. El diario. Disponible en: http://www.eldiario.es/desigualdadblog/refugiados-Europa-Turquia-Grecia-acuerdo_6_494910526.html Última consulta: 06/07/18.

Migraciones forzadas (2016). Orientación sexual e identidad de género y la protección de los migrantes forzados. Oxford: Oxford University.. Disponible en: http:// www.fmreview.org/sites/fmr/files/FMRRdownloads/es/osig/RMF42 completo. pdf Última consulta: 06/07/18.

Mustikhan, A. (2003, 4 de abril). Group Fights for Palestinian Gays's Safety. PlanetOut New Politics. Disponible en: http://www.planetout.com Última consulta: $06 / 07 / 18$

Said, E. (2001, 16 de octubre). El choque de ignorancias. El País.. Disponible en: https://elpais.com/diario/2001/10/16/opinion/1003183207_850215.html Última consulta: 06/07/18.0op 